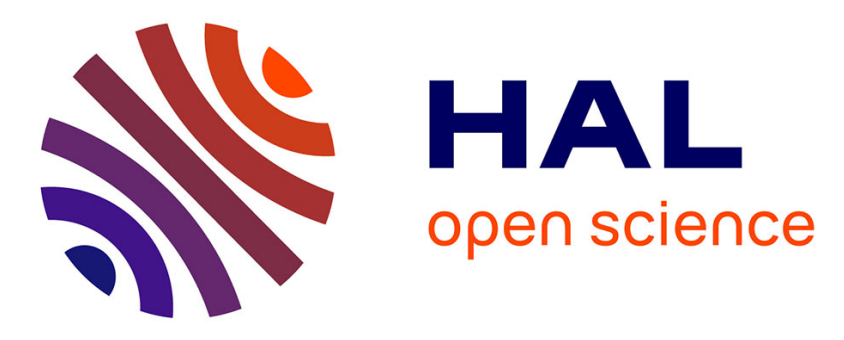

\title{
The impact of national integration policies on prejudice and psychological well-being: The fundamental role of the clarity and coherence of integration policies
} Roxane de La Sablonnière, Armelle Nugier, Nada Kadhim, Emmanuelle Kleinlogel, Mathieu Pelletier-Dumas, Serge Guimond

\section{To cite this version:}

Roxane de La Sablonnière, Armelle Nugier, Nada Kadhim, Emmanuelle Kleinlogel, Mathieu PelletierDumas, et al.. The impact of national integration policies on prejudice and psychological well-being: The fundamental role of the clarity and coherence of integration policies. European Journal of Social Psychology, 2020, 50 (3), pp.614-633. 10.1002/ejsp.2647 . hal-02978220

\author{
HAL Id: hal-02978220 \\ https://hal.science/hal-02978220
}

Submitted on 11 Dec 2020

HAL is a multi-disciplinary open access archive for the deposit and dissemination of scientific research documents, whether they are published or not. The documents may come from teaching and research institutions in France or abroad, or from public or private research centers.
L'archive ouverte pluridisciplinaire HAL, est destinée au dépôt et à la diffusion de documents scientifiques de niveau recherche, publiés ou non, émanant des établissements d'enseignement et de recherche français ou étrangers, des laboratoires publics ou privés. 
Running head: CLARITY AND COHERENCE

Running head: CLARTY AND COHERENCE

The Impact of National Integration Policies on Prejudice and Psychological Wellbeing: The Fundamental Role of the Clarity and Coherence of Integration Policies

European Journal of Social Psychology (2020). DOI: 10.1002/ejsp.2647

\author{
Roxane de la Sablonnière ${ }^{1}$ \\ Armelle Nugier ${ }^{2}$ \\ Nada Kadhim ${ }^{3}$ \\ Emmanuelle P. Kleinlogel ${ }^{4}$ \\ Mathieu Pelletier-Dumas ${ }^{3}$ \\ Serge Guimond ${ }^{2}$
}
Université de Montréal, Montréal, Québec, Canada ${ }^{1}$
Université Clermont-Auvergne, CNRS-UMR6024²
Université du Québec à Montréal, Canada ${ }^{3}$

Faculty of Business and Economics, University of Lausanne, Switzerland ${ }^{4}$

Correspondence concerning this article should be addressed to Roxane de la Sablonnière, Département de Psychologie, Université de Montréal, C. P. 6128, Succ. Centre-Ville, 
Montréal, P. Q., Canada, H3C 3J7. Email: roxane.de.la.sablonniere@umontreal.ca, Telephone: 514-343-6732, Fax: 514-343-2285.

Acknowledgements. This research was supported by grant from L'Agence Nationale de Recherche in France and from the Fond de Recherche Société et culture du Quebec under Grant ANR 11-FRQU-004-01. The authors wish to thank the participants of our studies who took their time to answer our questionnaire as well as Mathieu Caron-Diotte and Samuel Mérineau for their help in statistical analyses.

Conflict of Interest Statement. The authors declare that they have no conflict of interest.

Ethical Statement. The ethics boards of the Université de Montréal approved the study reported. All participants provided informed consent prior to participation.

Transparency Statement. The data presented in this research is available at https://doi.org/10.5683/SP2/JSSZW9 


\begin{abstract}
Recent advances in social psychological research have shown that national integration policies influence how immigrants are perceived and treated by the mainstream population. However, the processes by which these policies come to have an impact on prejudice and well-being of the general population are largely unknown. Moreover, past research has often relied on unrepresentative samples limiting generalizability. The present research proposes that when the national integration policies of a given society are perceived as clearly defined and coherent, they have a direct impact on the perceived cultural norm related to those national integration policies. In turn, the perceived cultural norm affects personal attitudes toward cultural norms (i.e., the degree to which individuals support a given policy), which influence the level of anti-immigrant prejudice as well as psychological well-being. Findings from two correlational studies with representative samples of the mainstream population conducted in France on the policy of secularism $(N=940)$ and in Québec on the policy of interculturalism $(N=912)$ supported the proposed theoretical model.
\end{abstract}

Keywords: national integration policies; interculturalism; secularism; personal attitudes; clarity; coherence; cultural norms; prejudice; well-being. 
The Impact of National Integration Policies on Prejudice and Psychological Wellbeing: The Fundamental Role of the Clarity and Coherence of Integration Policies

Dealing with cultural diversity and the integration of immigrants and refugees into society represents one of the biggest challenges of our times. For this reason, there are now several distinct policies that have been developed in various countries in order to manage intergroup relations in culturally plural societies (Koopmans, Statham, Giugni, \& Passy, 2005). In the present research, we focus on majority group members and examine how national integration policies may have an impact on the level of prejudice and well-being of the general population.

In the scientific literature, understanding the universal factors involved in both wellbeing (Diener, Diener, \& Diener, 1995; Diener \& Ryan, 2009; Sharma \& Sharma, 2010) and negative attitudes and prejudice toward outgroups, was the focus of research for several decades. For example, many of the explanations of prejudice that were proposed and tested by scientists involved individual factors such as Right-Wing Authoritarianism (RWA; Altemeyer, 1998), and Social Dominance Orientation (SDO; Pratto, Sidanius, Stallworth, \& Malle, 1994). The implication of this approach is that to change prejudice or to improve wellbeing, one needs to change the psychological characteristics of individuals.

One of the major insights of classical and more recent theoretical developments in social psychology, however, is the idea that to change individuals, it may be more effective to change the group (Blanchard, Crandall, Brigham, \& Vaughn, 1994; Festinger, 1950; Guimond, Dambrun, Michinov, \& Duarte, 2003; Sherif, 1953; Taylor, 2002). According to the self-categorization theory (Turner \& Reynolds, 2012), when people define themselves as group members, their behaviour is more likely to reflect the role of shared group norms rather than personal preferences (Verkuyten \& Hagendoorn, 1998). In line with this view, there is increasing evidence suggesting that changing the perceived group norms can have a major 
impact on intergroup relations (Crandall, Eshleman, \& O’Brien, 2002; Portelinha \& Elcheroth, 2016; Sechrist \& Stangor, 2001). But where do these group norms come from? Tankard and Paluck (2017) have nicely illustrated that enacting new policies and new laws can create new norms. They found that the U.S. Supreme Court decision regarding gay marriage had a significant impact on the perceived norm regarding gay marriage in the United States, as assessed in a five-wave longitudinal study, whereas it did not change personal attitudes toward gay marriage. The theoretical importance of this study lies in the fact that, contrary to previous research, their findings identify the institutional roots of the perceived norm.

The importance of group norms and their institutional roots has also emerged in research on the social and psychological impact of national integration policies on the general population (Guimond et al., 2013; Levin et al., 2012). National integration policies represent official rules and regulations put forward by governments to integrate migrants and manage relations between groups that differ in ethnic, racial, cultural, or religious background. The idea that such national integration policies represent a key contextual factor that can play an important role in framing people's thoughts when it comes to intergroup attitudes and behaviour was raised several decades ago (Berry, Kalin, \& Taylor, 1977). However, data supporting such a view was published only in recent years (Green, Visintin, Sarrasin, \& Hewstone, 2019; Guimond et al., 2013; Schlueter, Meuleman, \& Davidov, 2013). More specifically, after 40 years of research focussing on personal attitudes toward multiculturalism and assimilation, there is now strong evidence showing the importance of distinguishing between the perceived cultural or group norms, that is the perceived level of support in a country for a given national integration policy, from personal attitudes, that is the extent to which individuals personally support these norms (see Guimond, de la Sablonnière, \& Nugier, 2014; Guimond, Streith, \& Roebroeck, 2015; Pelletier-Dumas, de la Sablonnière, 
\& Guimond, 2017). Whereas national integration policies can have little direct impact on personal attitudes (Van de Vijver, Breugelmans, \& Schalk-Soekar, 2008), they can have a strong impact on the perceived cultural norms, and it is through these norms that they can shape how the population feels, thinks, and behaves toward immigrants (Anier, Badea, Berthon, \& Guimond, 2018; Guimond et al., 2013; Schlueter et al., 2013). However, it is unknown how the perceived cultural norms associated with national integration policies develop and why some norms have more of an impact than others. The goal of the present research is to provide, for the first time, an empirical test of a model outlining the process through which national integration policies and perceived cultural norms develop and shape people's intergroup attitudes and psychological well-being.

Based on the literature in the field of social psychology, we argue that the interaction between two key variables, the perceived clarity and the perceived coherence of the integration policy, play a pivotal role in influencing individuals' perceived cultural norms promoted by national integration policies. We propose that a combination of high perceived clarity and high perceived coherence of a national policy will shape the perceived cultural norms that will influence personal attitudes toward the norm (see Figure 1). Personal attitudes will in turn directly predict people's level of prejudice and feelings of psychological wellbeing. Importantly, we expect this model to be valid even when considering national integration policies that are very different from each other. For this reason, we will test the model using representative samples of the mainstream population from two distinct contexts that promote different national integration policies: Québec (interculturalism) and France (secularism or "laïcité"). Variations around the basic model can be expected as a function of changing local conditions. For example, there is evidence that the perceived cultural norm associated with a policy of multiculturalism have direct effects on prejudice, in addition to 
their indirect effects via personal attitudes toward the policy (see Guimond et al., 2013). The present research will also explore these variations.

\section{Clarity and Coherence of Integration Policies}

We propose that to better understand the process through which national integration policies influence perceptions of cultural norms, two key factors in interaction need to be considered: perceived clarity and perceived coherence of national integration policies. Before presenting our theoretical reasoning in this regard, we review the literature of each concept in turn. This is because perceived clarity and perceived coherence emerged from different theoretical perspectives and that it is just recently that they have been theorized to be influential conjointly (Kleinlogel, Nugier, Pelletier-Dumas, de la Sablonnière, \& Guimond, 2019).

The concept of "clarity" has been used in different domains of research in social psychology, such as in the field of attributions (i.e., attributional clarity, causal uncertainty, attributional ambiguity; e.g., Thompson \& Hepburn, 2003), attitudes (i.e., attitude clarity; Petrocelly, Tormala, \& Rucker, 2007), social norms (Zitek \& Helb, 2007), the organisational setting (Cole, Harris, \& Bernerth, 2006), personal identity (i.e., personal identity clarity; Campbell, 1990), and collective (or cultural) identity clarity (Taylor \& de la Sablonnière, 2014). In general, authors using "clarity" as a central concept postulated that it plays a critical role in internalizing who we are as an individual or as a group member. For example, research has demonstrated that for employees, a clear vision of changes occurring in their organization was related to positive job-related outcomes such as job satisfaction and organizational commitment (Cole et al., 2006).

Applied to the context of national integration policies, the concept of clarity refers to the degree to which national integration policies are perceived as clearly defined and explained. In Québec/France, if people do not understand the goal behind 
interculturalism/secularism and how interculturalism/secularism promotes the integration of immigrants into society, they might perceive the national integration policies as unclear. This perception of lack of clarity might also be accentuated by public debates that create controversy such as "reasonable accommodation in Québec", in which immigrants asked for special treatments and exceptions based on their cultures and religions, or the commission presided by Bernard Stasi in France whose report in 2003 led to the 2004 law banning religious symbols among public school children in France (Akan, 2009). Such debates in the media might thus influence how clearly individuals perceive national diversity policies and thus perceived cultural norms. To maintain a positive personal identity and well-being, individuals would be motivated to personally support clear and well-defined national diversity policies and the associated norms. Hence, unclear policies may threaten the internalization of cultural norms. This position is consistent with several researchers who have emphasized the central role of cultural norms (Rubin \& Hewstone, 1998; Tajfel, 1982; Tesser, 2003; Turner, Hogg, Oakes, Reicher, \& Wetherell, 1987).

In addition to perceived clarity, we also propose that the perceived "coherence" of a national integration policy plays a crucial role in shaping the perceived norm and individuals' personal attitudes toward this policy. The concept of coherence is present in many theories ranging from cognitive theories such as cognitive dissonance theory (Festinger, 1957) to theories associated with identity, acculturation (Berry, 1990), biculturalism (Benet-Martinez \& Haritatos, 2005), and identity integration (Amiot, de la Sablonnière, Terry, \& Smith, 2007). This research tells us that coherence between different information presented simultaneously, achieves well-being and facilitates their integration to the self. For example, it allows individuals to avoid experiences of psychological discomfort (Festinger, 1957) and to derive meaning from their lives, through for instance, coherent story telling (Baerger \& McAdams, 1999; McAdams, 1993). 
Applied to national integration policies, the concept of coherence is defined as the extent to which a government proposal concerning the integration of immigrants is seen as compatible with other related government proposals in the same context or fitting with the general ideology of the country. When government proposals regarding the integration of immigrants are inconsistent, people might be less motivated to personally support the cultural norms since it would be impossible to maintain a coherent identity. For example, a formal national integration policy (i.e., a public policy) can promote something that contradicts informal cultural norms in a society (e.g., in France, secularism may seem to be contradictory since historical secularism promotes integration, while new secularism does not). As a consequence, the influence of public policy would be weaker, increasing the likelihood that citizens reject the various government proposals and implanting the belief that very few people in the country support such a policy. Thus, the effectiveness of public policies depends on the consistency of every standard proposed (i.e., national diversity policies and the cultural norms regarding immigrants).

In the present research, we suggest that it may be particularly important to consider clarity and coherence in interaction when studying national integration policies. Why would somebody be in favour of a policy that is neither clear nor coherent? In such a case, one may infer that there is little support in the population. In contrast, when a policy is perceived as both clearly spelled out (high clarity) and very well integrated with other policies (high coherence), one is likely to estimate that the policy is widely supported by fellow ingroup members, and thus highly normative in the country.

The model represented in Figure 1 predicts that, within any given country, perceiving clearly defined national integration policies (i.e., perceived clarity) that do not contradict each other (i.e., perceived coherence) leads to the perception of strong support for the policy within the population. It is possible that perceived clarity and perceived coherence 
independently influence perceived cultural norms. However, initial evidence (Kleinlogel et al., 2019) revealed an interaction effect between the perceived clarity and the perceived coherence of a proposed law predicting individuals' personal attitudes toward this law. For instance, it was observed in the French context that the perceived coherence was associated with greater support when the perceived clarity was high, as expected. Therefore, in the present research we were interested in testing the hypothesis that high clarity may elevate the perceived level of support for a given policy (i.e., the perceived norm) when associated with high coherence but not when it is associated with low coherence. Specifically, we argue that perceived clarity and perceived coherence have a combined or additive impact. Thus, a policy that is perceived as highly coherent with other norms and policies may be more strongly supported than one that is incoherent. However, this impact is expected to depend on the perceived clarity such that when it is clear and coherent, it should be related to even more support than if it is coherent and unclear. In the latter case, people may wonder if the coherence is more apparent than real. The lack of clarity introduces ambiguity that can lead to greater reservation in one's judgment. In other words, perceived clarity can be expected to increase favorable judgments when the policy is perceived as high in coherence but it can also be expected to increase unfavorable judgments when the policy is perceived as lacking in coherence. Thus, we argue that the influence of perceived clarity of integration policies will interact with that of perceived coherence in shaping the perceived cultural norm.

\section{Interculturalism and Secularism: The Political Context}

Before explaining in more detail our model and predictions, it is necessary to consider the political context of this study. Past research has emphasized two broad categories of national integration policies: assimilation and multiculturalism (Guimond et al., 2014). These two categories differ in the degree to which they are open toward diversity. On the one hand, assimilation promotes the disappearance of cultural differences across groups by encouraging 
immigrants to abandon their cultural characteristics such as their mother tongue and to adopt the language of the host country (Moghaddam, Taylor, \& Wright, 1993). Multiculturalism, on the other hand, promotes cultural diversity and invites immigrants to keep their cultural characteristics (Guimond et al., 2014).

The present studies take place in the Canadian province of Québec and in France, where the official national integration policy is neither multiculturalism nor assimilation, but interculturalism and secularism, respectively. Interculturalism was developed in Québec in response to the Canadian multicultural model introduced in the 70's in Canada (Bouchard \& Taylor, 2008). For the present purpose, we will assume that Québec can be considered a nation, at least in the sociopolitical sense. As mentioned by Seymour (2000), a nation can be defined as a community with a certain self-representation shared by a large portion of individuals within the community.

Since the 1980s, interculturalism is considered to be the main national integration policy in Québec (Gagnon \& Iacovino, 2007). What interculturalism means and the extent to which it is distinct from multiculturalism, have been hotly debated in the last several decades (Kymlicka, 2012; Modood \& Meer, 2012). Interculturalism and multiculturalism are both pluralistic mindsets that recognize and value the existence of different ethnic groups. However, interculturalism places emphasis on dialogue and interactions between groups, whereas multiculturalism implies recognition of group differences without necessarily fostering interactions between these groups. Indeed, a major difference between these two integration policies is that multiculturalism in Canada does not explicitly acknowledge the existence of a majority culture (i.e., "diversity defines the country"; Bouchard, 2011, p. 463) whereas interculturalism does. In Québec, the national integration policy underlines the existence of a francophone majority and it seeks to foster intensive exchanges and interactions between the majority and cultural minorities through the use of a common 
language (Bouchard, 2011). Thus, Québec's intercultural model promotes cultural diversity, as does multiculturalism but it also explicitly encourages immigrants to integrate into society by learning the French language (Rocher \& White, 2014).

Empirical research on interculturalism is scarce (Scott \& Safdar, 2017). In 2008, an important proposal was put forward by the Council of Europe in order to replace multiculturalism by interculturalism. This proposal was supported by all members of the European Union (Verkuyten, 2016). Yet, it was made without any evidence about the impact of interculturalism on intergroup relations (Kymlicka, 2012). The present research will provide a significant input into this debate by offering the first comprehensive empirical test of the value of interculturalism in a society that has promoted such a model over the last 20 years using a representative sample of the mainstream population.

In addition, because the proposed theoretical model is expected to be useful to understand the impact of any integration policy, not only interculturalism, it will also be tested in France, certainly a different national context given its policy of secularism. Social scientists have described at length the particular features of the French model of integration, setting it apart from assimilation, multiculturalism, or interculturalism (Guimond et al., 2014). It can be summarized as being a colorblind model (Bleich, 2001). The idea of colorblindness refers to the ideology that group differences are not important and should be ignored. This ideology characterizes the French model through the principles of secularism and citizenship stated in the French Constitution of 1958. These principles aim to ignore group-based differences (e.g., religion, ethnicity) between individuals through the neutral position of the state in terms of religion and by allocating equal rights and duties to each individual (Schnapper, 2004).

Secularism has been present in France since the beginning of the $18^{\text {th }}$ century. It is now referred to as "laïcité" (Kamiejski, Guimond, De Oliveira, Er-Rafiy, \& Brauer, 2012). 
Historically, secularism was introduced in France to ensure equality among all citizens and guarantee their freedom of conscience, regardless of their background, ethnicity, and religion (i.e., historical secularism). If this conception of secularism still exists and is strong within the French population, another conception has been rising over the last decade resulting in what Baubérot (2012) called a "new secularism." New secularism reflects the idea that religious practices should be kept private as much as possible and not public (see Kamiejski et al., 2012; Roebroeck \& Guimond, 2016, 2018). Contrary to historical secularism, new secularism applies the principle of neutrality not only to state representatives in accordance with the law of 1905 but also to individual citizens, even when they are not agents of the State (such as in the 2004 law, banning conspicuous religious signs among all pupils in public schools, or in the law 2010, banning face coverings in public spaces). It can be argued that these recent laws banning religious signs are specifically targeting religious minorities (particularly the Muslims), and so amounts to the stigmatization of Muslims in France (see Baubérot, 2012; Nugier et al., 2016; Roebroeck \& Guimond, 2015; Troian, Bonetto, Varet, Barbier, \& Lo Monaco, 2018). Indeed, psychological research has empirically documented that support for "new secularism" is positively related with anti-immigrant prejudice whereas support for "historic secularism", in contrast, is strongly and negatively related with antiimmigrant prejudice (Kamiejski et al., 2012; Nugier et al., 2016; Roebroeck \& Guimond, 2016, 2018). Thus, today in France, the principle of secularism is a principle with dualintergroup meanings, "new secularism" and "historic secularism", each having extremely different implications for intergroup relations.

\section{Perceived Cultural Norms, Personal Attitudes, Prejudice, and Well-Being}

Does national integration policy of interculturalism in Québec and secularism in France increase or decrease anti-immigrant prejudice? Our theoretical predictions here are based on social dominance theory's classification of integration policies as hierarchy- 
enhancing or hierarchy-attenuating (Pratto, Sidanius, \& Levin, 2006; Sidanius \& Pratto, 2012). Specifically, Levin et al. (2012) have shown that hierarchy-enhancing policies that are seeking to reinforce and maintain group-based inequality, such as assimilation, are associated with increased prejudice toward ethnic minorities whereas hierarchy-attenuating policies that promote equality, such as multiculturalism or colorblindness, are, to the contrary, associated with reduced prejudice. Because interculturalism is a policy that is close to multiculturalism, it can be classified as hierarchy-attenuating and thus be expected to be related with reduced anti-immigrant prejudice. For secularism in France, previous research has suggested that historical secularism has a strong egalitarian component and thus can be classified as hierarchy-attenuating whereas new secularism appears to be an evolving hierarchy-enhancing policy (Roebroeck \& Guimond, 2016, 2018). Consequently, we expect that support for historical secularism will predict lower levels of prejudice whereas support for new secularism will be associated with increased prejudice toward ethno-religious minorities.

Finally, an original feature of the proposed model is to argue not only for an association between personal support for a given integration policy and prejudice, as suggested in past research, but also for a role in the explanation of psychological well-being. Well-being has emerged in recent years as a significant criterion by which to judge the effectiveness of government interventions. It has been argued that an effective policy should not only be economically sound; it should also increase the well-being of the people. Thus, we suggest that a national integration policy that is in tune with citizen's needs and values is likely to be reflected in a greater well-being within the population. To our knowledge, very little research has explored that association from the perspective of the majority, sometimes referred to as the host population (for an exception see Jackson and Doerschler, 2016).

Numerous research has found a positive link between "integration" as an inclusive acculturation strategy, and the well-being of immigrants and minority groups (Berry, 
Phinney, Sam, \& Vedder, 2006). We similarly hypothesize a positive association between personal attitudes toward hierarchy-attenuating policies and the well-being of majority group members. More specifically, hierarchy-attenuating policies are associated with equality and inclusion. Equality and inclusion foster feelings of belonging (Schachner, He, Heizmann, \& Van de Vijver, 2017). The need to belong, the sense that one is part of the group or society, is a key to well-being (Baumeister \& Leary, 1995). Thus, we expect that support for hierarchyattenuating policies such as interculturalism and historical secularism will be positively related to well-being.

This hypothesis on well-being is important and suggests that national integration policies are central in promoting not only tolerance and integration of immigrants into society but also the well-being of all, including the majority of people. If the positive association between an "open" national integration policy and well-being is demonstrated, leaders may use these results to promote such policies. Well-being touches members of the majority group directly contrary to prejudice that might seem less important to them. Our hypothesis that inclusive integration policies can improve the well-being of majority group members is supported by the recent findings of Jackson and Doerschler (2016). Across 14 European countries, they find that the more inclusive and multicultural the policy is, the more satisfaction with life there is among the general population. This finding, at the national-level, is consistent with our assumptions. However, it does not provide any direct psychological link to support the idea that well-being is shaped by the policy nor the process that leads to the increase or decrease of well-being. This is what we attempt to contribute here by directly measuring perceived cultural norms and personal attitudes related to two distinct inclusive policies, interculturalism in Québec and historical secularism in France. In contrast, we do not expect such positive association for new secularism in France because only hierarchyattenuating policies promoting openness and equality are expected to lead to greater well- 
being. Previous research suggests that new secularism in France is not hierarchy-attenuating. We expect the association between new secularism and well-being to be non-existent or even negative.

\section{Proposed Model and Hypotheses}

In this research, we use two representative samples of the mainstream population within two distinct national contexts that promote different national integration policies. As a preliminary test, we will explore the idea that the national integration policy in France is organized around the principle of secularism (laïcité) more than is the case in Québec, and that the national integration policy in Québec is organized around the principle of interculturalism more than is the case in France. To this end, we will contrast the reactions of the general population in Québec and in France toward four key concepts representing four integration policies: multiculturalism, assimilation, interculturalism, and secularism. If interculturalism is indeed the main policy in Québec, then the population of Québec should rate the concept of interculturalism more positively than French people. Conversely, if the main policy in France is secularism, then this concept should be rated more positively by the French population than by the Québec population.

The main goal of the present research is to propose and test a model of the impact of clarity and coherence of national integration policies on group members' attitudes and wellbeing (see Figure 1). The present theoretical approach seeks to integrate within the same overarching explanation specific contextual elements that can differ widely across different settings (Guimond et al., 2014; Roebroeck \& Guimond, 2018; Sedikides, Gaertner, \& Toguchi, 2003) by evaluating perceived cultural norms and personal attitudes specific to each nation (interculturalism in Québec and secularism in France). In our research, we argue that the psychological processes, however, would be the same such that, for example, the role of perceived clarity and coherence of integration policies would be similar in both contexts 
although the national integration policy is different. Specifically, as illustrated in Figure 1, we predict that the more a national integration policy is perceived as clear and coherent, the more likely it is to foster the belief that people in the country are in agreement with the policy (perceived cultural norms). This normative belief is then expected to increase personal support for the integration policy. In turn, the personal attitudes toward cultural norms will have consequences on both prejudice toward immigrants and well-being.

\section{Method}

\section{Participants and Procedure}

The same polling firm was used to recruit a thousand participants by internet in Québec and in France. Our sample size was determined based on the minimum sample size required for structural equation modeling (i.e., $N=200$; Kline, 2016) and on the fact that we were looking for a representative sample of the general population in each country.

Participants were invited to take part in an online questionnaire that took about 30 minutes to complete.

To obtain the two representative samples, the polling firm selected 1000 participants in each study from an initial pool based on a sampling frame on population gender, age, education, and residence provided by Insee (Institut national de la statistique et des études économiques) in France and by the Canadian Census data of Québec. Out of the 1000 participants for each country, we have excluded immigrants, i.e., those who were not born in Québec or in France. Thus, the final data sample consisted of 912 participants in Québec and 940 in France, which represent the mainstream population in each of these contexts. In the Québec sample $\left(M_{\mathrm{age}}=48.03, S D=15.27\right.$; range: 18 to 88$), 52.2 \%$ were females. In addition, 98.1\% of Québec sample were French Quebecers, 0.9\% Anglophone Quebecers, and 1\% were from Aboriginal communities or other minority groups. In the French sample $\left(M_{\mathrm{age}}=\right.$ 47.04, $S D=15.1$; range: 18 to 99$), 48.9 \%$ were females. 


\section{Measures}

Unless otherwise noted, participants indicated their response using a 5-point Likerttype scale $(1=$ strongly disagree to $5=$ strongly agree $)$. All materials were in French.

Evaluative meaning of four integration policies. To provide evidence directly relevant to our assumption about the nature of the integration policies in each country, we asked participants to indicate if they attached negative or positive evaluative meaning to the following four concepts, each representing a given integration policy by one word: "secularism (Laïcité in French)", "interculturalism", "multiculturalism”, and "assimilation." These ratings were made on a 4 -point scale $(1=$ very negative, $4=$ very positive $)$. Participants also had the option of indicating that they did not know what this policy meant.

Clarity and coherence of integration policies. In our research, we could not find existing measures directly related to clarity and coherence of integration policies. Accordingly, we decided to adapt existing measures close to our topic. From an initial pool of 6 items adapted from the Cultural Identity Clarity Scale (Usborne \& Taylor, 2010), we used 2 items to assess perceived clarity of integration policies $\left(r_{\text {Québec }}=.55, p<.001 ; r_{\text {France }}=.58, p\right.$ $<.001$; see Table 1 for the exact wording). We measured the perceived coherence of integration policies $(\alpha$ France $=.85 ; \alpha$ Québec $=.85)$ using 4 items (see Table 1$)$ adapted from the Integration subscale of the Multicultural Identity Integration Scale (Yampolsky, Amiot, \& de la Sablonnière, 2016).

Confirmatory Factor Analyses (CFA) conducted separately on the data from Québec and on the data from France confirmed the validity of the measures of perceived clarity and perceived coherence. It should be noted that factors within each CFA model of this research were allowed to covary. As recommended by Kline (2016), a total of four fit indices are used to test the adequacy of the models with the data. Along with the $\chi^{2}$ and its associated $p$-value, 
we expect the Comparative Fit Index (CFI) to be superior or equal to .90 and ideally $\geq .95$, the Root Mean Square Error of Approximation (RMSEA) should be $\leq .08$ and the Standardized Root Mean Square Residual (SRMR) should be $\leq .10$. The fit indices of the overall models distinguishing perceived clarity and perceived coherence were adequate in Québec $\left(\chi^{2}[8]=33.28, p<.001 ; \mathrm{CFI}=.99 ; \mathrm{RMSEA}=.06 ; \mathrm{SRMR}=.02\right)$ and in France $\left(\chi^{2}\right.$ $[8]=56.83, p<.001 ; \mathrm{CFI}=.98 ; \mathrm{RMSEA}=.08 ; \mathrm{SRMR}=.03)$. In Québec, the standardized factor loadings varied between .69 and .80 for clarity and between .66 and .86 for coherence. In France, they ranged from .66 to .88 for clarity and from .66 to .87 for coherence. All factor loadings were significant at $p<.001$.

Perceived cultural norms. Given that past research has focused on assimilation and multiculturalism as integration policies, and given our claim that the policies in France and in Québec are distinct, there is a requirement to show that our measures of secularism and interculturalism are indeed tapping into something different from assimilation and multiculturalism. Consequently, we included measures of assimilation and multiculturalism in addition to the measures of secularism (historical and new) and interculturalism (see Table 2). All scales of perceived cultural norms contained 4 items. Correlations between all five measures of perceived norms are presented in Table $\mathrm{S} 1$ of the supplementary materials.

We measured perceived norms of new secularism $(\alpha$ France $=.76 ; \alpha$ Québec $=.80)$ and of historical secularism $(\alpha$ France $=.82 ; \alpha$ Québec $=.75)$ with scales adapted from Kamiejski et al. (2012; see also Roebroeck \& Guimond, 2016). The interculturalism scale was created based on results from a preliminary study conducted in Québec $(N=53)$ that combined theoretical considerations, exploratory factor analysis, and internal consistency analysis. Initially, 11 items were created from consulting Rocher, Labelle, Field, and Icart (2007) as well as Bouchard (2012). In selecting the final items for the main studies, we kept in mind the length of the questionnaire while making sure that enough items were chosen for 
structural equation modeling for our main analyses. A total of four items was selected. The Cronbach alpha for perceptions of interculturalism norm in the present research was .77 in Québec and .78 in France. Both French and Quebecers also reported their perception of the norm of assimilation $(\alpha$ France $=.77 ; \alpha$ Québec $=.77)$ and multiculturalism $(\alpha$ France $=.84$; $\alpha$ Québec $=.82)$. These items were taken from Guimond et al. (2013) and were assessed in order to validate our scales.

In making sure that the perceived cultural norms scales were assessing different types of cultural norms, we performed two CFAs, one for Québec and one for France. Results of CFAs on all five measures of norms together showed acceptable fit indices in Québec $\left(\chi^{2}\right.$ $[160]=521.45, p<.001 ; \mathrm{CFI}=.94 ; \mathrm{RMSEA}=.05 ; \mathrm{SRMR}=.06)$ and in France $\left(\chi^{2}[160]=\right.$ 653.47, $p<.001 ; \mathrm{CFI}=.93 ; \mathrm{RMSEA}=.06 ;$ SRMR $=.06)$. In Québec, standardized factor loadings ranged from .73 to .74 for multiculturalism, from .48 to .85 for assimilation, from .57 to .77 for interculturalism, from .66 to .77 for new secularism, and from .58 to .74 for historical secularism. In France, standardized factor loadings varied between .72 to .80 for multiculturalism, between .44 to .85 for assimilation, between .60 to .77 for interculturalism, between .64 to .72 for new secularism, and between .67 and .78 for historical secularism. All factor loadings were significant at $p<.001$. Two identical alternative models were tested in each country. More specifically, "open” perceived cultural norms, namely, interculturalism, multiculturalism, and historical secularism were collapsed together under one latent variable. In addition, "closed" perceived cultural norms (i.e., assimilation and new secularism) were put together under a latent variable. These models yielded poor fit indices in both Québec $\left(\chi^{2}\right.$ $[169]=2469.511, p<.001 ; \mathrm{CFI}=.64 ; \mathrm{RMSEA}=.12 ; \mathrm{SRMR}=.14)$ and in France $\left(\chi^{2}[169]\right.$ $=2435.258, p<.001 ; \mathrm{CFI}=.70 ; \mathrm{RMSEA}=.12 ; \mathrm{SRMR}=.13)$. Additionally, $\Delta \chi^{2}$ tests showed that these models differed significantly from the original models in both Québec ( $\Delta$ $\left.\chi^{2}[9]=1948.07, p<.001\right)$ and in France $\left(\Delta \chi^{2}[9]=1781.79, p<.001\right)$. These significant 
differences indicate that the original models fit the data better than the alternative ones, supporting the validity of our measures and conceptualization of perceived norms.

Personal attitudes. Personal attitudes toward new secularism $(\alpha$ France $=.78 ; \alpha$ Québec $=.83)$, historical secularism $(\alpha$ France $=.86 ; \alpha$ Québec $=.83)$, interculturalism $(\alpha$ France $=.84 ; \alpha$ Québec $=.81)$, assimilation $(\alpha$ France $=.79 ; \alpha$ Québec $=.79)$, and multiculturalism $(\alpha$ France $=.85 ; \alpha$ Québec $=.83)$, were adapted from the perceived cultural norms items using similar items. All scales of personal attitudes contained 4 items. Also, in the personal attitudes questions, in contrast to the measures of perceived norms, participants were requested to express their own personal opinion and not the perceived opinion of other French/Quebecers (see Table 3). Correlations between all five measures of personal attitudes are presented in Table $\mathrm{S} 2$ of the supplementary materials.

We performed two final CFAs on personal attitudes toward all five policies in Québec and in France. Results showed adequate fit indices in Québec $\left(\chi^{2}[160]=722.36, p<.001\right.$; $\mathrm{CFI}=.93 ; \mathrm{RMSEA}=.06 ; \mathrm{SRMR}=.07)$ and in France $\left(\chi^{2}[160]=836.49, p<.001 ; \mathrm{CFI}=\right.$ $.93 ;$ RMSEA = .07; SRMR = .08). In Québec, standardized factor loadings varied between .71 and .75 for multiculturalism, between .47 and .86 for assimilation, between .65 and .79 for interculturalism, between .69 and .81 for new secularism, and between .65 and .79 for historical secularism. In France, standardized factor loadings ranged from .75 to .79 for multiculturalism, from .45 to .86 for assimilation, from .66 to .85 for interculturalism, from .64 to .78 for new secularism, and from .69 to .84 for historical secularism. All factor loadings were significant at $p<.001$. The same alternative models as with perceived cultural norms were tested with personal attitudes as well. Similar results were obtained. The alternative models resulted in poor fit indices in both Québec $\left(\chi^{2}[169]=3114.989, p<.001\right.$; $\mathrm{CFI}=.63 ; \mathrm{RMSEA}=.14 ; \mathrm{SRMR}=.16)$ and in France $\left(\chi^{2}[169]=2732.837, p<.001 ; \mathrm{CFI}=\right.$ $.72 ; \mathrm{RMSEA}=.13 ; \mathrm{SRMR}=.13)$. In addition, $\Delta \chi^{2}$ tests showed that these models differed 
significantly from the original models in both Québec $\left(\Delta \chi^{2}[9]=2392.63, p<.001\right)$ and in France $\left(\Delta \chi^{2}[9]=1896.35, p<.001\right)$. These significant differences show that the original models are preferable.

In sum, there is support for the fact that measures of secularism and interculturalism (at the level of personal attitudes and perceived norms) reflect genuinely distinctive policies and not simply different labels for multiculturalism and assimilation.

Prejudice. We measured prejudice toward immigrants $(\alpha$ France $=.82 ; \alpha$ Québec $=$ .77) using 6 items (e.g., Personally, I would have no problem moving into a neighbourhood where many immigrants live, reversed item) adapted from previous research conducted in France and in other countries (Berry \& Kalin, 1995; Dambrun \& Guimond, 2001; PelletierDumas et al., 2017; Zick, Küpper, \& Hövermann, 2011; for the exact wording see Table S3 of the supplementary materials).

Psychological well-being. We assessed psychological well-being using two scales. First, we included the Life Sastisfaction Scale (Diener, Emmons, Larsen, \& Griffin, 1985; translation by Blais, Vallerand, Pelletier, \& Brière, 1989), composed of 5 items. A sample item is: "The conditions of my life are excellent" $(\alpha$ France $=.89 ; \alpha$ Québec $=.90)$. Second, we used the Subjective Authentic-Durable Happiness Scale (SA-DHS; $\alpha$ France $=.96 ; \alpha$ Québec $=.97$ ) by Dambrun et al. (2012). This scale consists of a list of 13 words or expressions (e.g., overall well-being, happiness, pleasure, satisfaction) and we asked participants to rate them according to how they feel in their current life on a 5-point scale $(1=$ very low, $5=$ very high).

\section{Data Analysis}

We conducted six steps to our data analysis. First, we did preliminary, descriptive, and correlational analyses to make sure that the data were well distributed and to report basic descriptive and correlational statistics. Second, we explored the nature of the national 
integration policies in Québec and in France with ANOVAs. This step is important to further explore each group in terms of national integration policies as well as to compare the two groups together. Here, the goal is to test the hypothesis that Québec and France can be distinguished in terms of their national integration policies. In meeting our main goal, the third step aims at testing the predictive models with Structural Equation Modeling (SEM). The two main models we tested were interculturalism in Québec and the secularism model, which includes historical secularism and new secularism, in France. Finally, we explored other direct effects in the fourth step, an alternative model where the interaction between clarity and coherence of integration policies would be predicted by perceived cultural norms in the fifth step as well as analyses exploring the unique nature of interculturalism in the sixth step.

\section{Results}

Preliminary analyses showed that the data were normally distributed given that all values of skewness and kurtosis are considered normal, smaller than 3 for skewness, and smaller than 10 for kurtosis (Kline, 2016). Tables 4 and 5 summarize the correlations among variables and the descriptive statistics in Québec and France, respectively.

\section{Preliminary Test: The Nature of the Policies Implemented in Québec and in France}

Québec and France are two western societies that are similar in several respects. Nevertheless, in the present research, we assume that a critical difference between Québec and France having important psychological implications is that secularism is more central in the French political model whereas interculturalism is more central in Québec. To empirically test our assumption, participants in both countries were asked to evaluate the connotation (i.e., positive or negative) of the four national integration policies of assimilation, multiculturalism, secularism, and interculturalism. Table 6 indicates the mean scores obtained by country. In France, as expected, a repeated measures ANOVA indicated that more positive 
value was attached to "secularism" than any other models (all $p$ s $<.001$ ). Moreover, the value of secularism in France is predicted by the two perceived cultural norms, new secularism and historical secularism (see supplemental material Table S4). In Québec in contrast, a repeated measures ANOVA showed that "interculturalism" was evaluated as positively as "secularism" (and "multiculturalism") and significantly more positively than "assimilation" $(p<.001)$. Across countries, one-way ANOVAs indicated that "secularism" was perceived more positively in France than in Québec $(p<.001)$, whereas "interculturalism" was perceived more positively in Québec than in France $(p<.001)$. In addition, the perceived interculturalism norm is a strong predictor of the positive evaluation of the concept of “interculturalism” in Québec (see supplemental material Table S5). This evidence supports our argument that the distinctive political model in France is organized around secularism more than in Québec whereas the distinctive model in Québec involves "interculturalism" more than in France. Further evidence about the integration policies actually promoted within each country is obtained by considering the mean scores on the perceived cultural norms related to the different policies (see Guimond et al., 2013; see supplemental material Table S6).

\section{Testing the Predictive Model}

To test the proposed model (Figure 1), we used SEM with AMOS v.20 and maximum likelihood estimation. Parameters are estimated and reported with 95\% confidence intervals and using percentile bootstrap sampling with 10,000 resamples. Based on recent advances in SEM, we have parcelled the items from the scales that had more than 5 items (prejudice and subjective authentic-durable happiness scales; Little, Cunningham, Shahar, \& Widaman, 2002; Matsunaga, 2008). The goal of this procedure is to limit the number of observed variables per latent variable to a manageable number (three per latent variable). For the prejudice scale, the item-to-construct balance method (Little et al., 2002) was used. This 
method creates balanced parcels by performing an exploratory factor analysis on a given scale and regrouping items that have low factor loadings with high factor loadings. Given that the number of items of the prejudice scale was limited (i.e., six), this method of parcelling allowed the weight of the factor loadings to be balanced. The prejudice scale has six items, thus, three 2-item parcels were created. In addition, given that factor loadings differed in each context, different parcels were created for Québec (parcel 1: items 2 and 6; parcel 2: items 1 and 5; parcel 3: items 3 and 4) and for France (parcel 1: items 1 and 6; parcel 2: items 3 and 4; parcel 3: items 2 and 5). For the subjective authentic-durable happiness scale, the random assignment method (Little et al., 2002) was used to create three parcels (i.e., parcel 1: items 4, 9, 10, 11, and 12; parcel 2: items 2, 3, 5, and 6; parcel 3: items 1, 7, 8, and 13). Given the high and uneven number of items (i.e., 13) in this scale, the random assignment method of parcelling was deemed preferable.

First, using the same fit indices as in the CFAs on the measures, we tested the model of interculturalism in Québec (see Figure 2). Results indicate acceptable model fit: $\chi^{2}(289)=$ $1034.97, p<.001 ; \mathrm{CFI}=.95 ; \mathrm{RMSEA}=.05 ; \mathrm{SRMR}=.05$. As predicted, the interaction term between the clarity and coherence of integration policies was significantly related to the perceived cultural norm $(b=0.09, \beta=0.13, p<.001,95 \%$ CI $[0.02,0.17]$, see Figure 3$)$. This result is in line with our prediction. Furthermore, as expected, the perceived cultural norm of interculturalism predicted positively personal attitudes toward interculturalism $(b=0.93, \beta=$ $0.72, p<.001,95 \%$ CI $[0.76,1.31])$. Finally, personal attitudes toward interculturalism predicted prejudice negatively $(b=-0.66, \beta=-0.71, p<.001,95 \%$ CI $[-0.75,-0.59])$ and psychological well-being positively $(b=0.17, \beta=0.20, p<.001,95 \%$ CI $[0.08,0.25])$.

Second, we tested the secularism model in France (see Figure 4). This model is somewhat more complicated than the previous one because the French policy of secularism consists of two distinct components (historical and new secularism). The fit indices of this 
model were also adequate: $\chi^{2}(511)=2385.63, p<.001 ; \mathrm{CFI}=.90 ; \mathrm{RMSEA}=.06 ; \mathrm{SRMR}=$ .08. The interaction term between the clarity and coherence of integration policies was significantly related to perceptions of the cultural norm of historical secularism $(b=0.06, \beta=$ $0.09, p=.019,95 \% \mathrm{CI}[0.00,0.14]$; see Figure 5) and perceptions of the cultural norm of new secularism $(b=0.13, \beta=0.19, p<.001,95 \%$ CI [0.07, 0.22]; see Figure 6). The results of Figure 5 are in line with our predictions whereby high clarity combined with high coherence would be associated with higher levels of perceived cultural norms of historical secularism. The results of Figure 6, however, go against our prediction in the sense that the perceived cultural norms of new secularism are the highest when clarity is low. Furthermore, perceptions of the cultural norm of historical secularism by group members predicted personal attitudes toward historical secularism positively $(b=0.63, \beta=0.65, p<.001,95 \%$ CI $[0.49,0.77])$. Perceptions of support of new secularism by group members also predicted personal attitudes toward new secularism positively $(b=0.90, \beta=0.90, p<.001,95 \% \mathrm{CI}$ $[0.78,1.03])$

Moreover, personal attitudes toward historical secularism predicted prejudice negatively $(b=-0.77, \beta=-0.57, p<.001,95 \%$ CI $[-0.89,-0.67])$ and psychological wellbeing positively $(b=0.12, \beta=0.15, p<.001,95 \% \mathrm{CI}[0.04,0.21])$, demonstrating that supporting an inclusive national integration policy such as historical secularism is associated with positive attitudes toward outgroup members and less prejudice toward them. Furthermore, as hypothesized, positive personal attitudes toward historical secularism are associated with more well-being among individuals. Finally, personal attitudes toward new secularism predicted prejudice positively $(b=0.39, \beta=0.29, p<.001,95 \%$ CI $[0.29,0.48])$, supporting our hypothesis and showing that endorsing a national integration policy that is more restrictive of diversity is linked with more prejudice and negative attitudes toward outgroup members. In addition, and in line with our expectations, no link was observed 
between personal attitudes toward new secularism and psychological well-being $(b=-0.03, \beta$ $=-0.03, p=.432,95 \%$ CI $[-0.10,0.06])$. Thus, overall, interculturalism and historical secularism were associated with more well-being among individuals but this was not the case for personal attitudes toward new secularism.

\section{Exploring Indirect Effects}

To complement our statistical analysis and to explore variations as a function of changing local conditions, we ran models requesting estimations for indirect effects while accounting for direct effects. In Québec, three direct paths were added to the model: 1) interaction between clarity and coherence of integration policies on personal attitudes toward interculturalism, 2) perceived cultural norm of interculturalism on well-being, and 3) perceived cultural norm of interculturalism on prejudice. The overall fit of the model were similar to our proposed and final model: $\chi^{2}(286)=1034.32, p<.001 ; \mathrm{CFI}=.95 ; \mathrm{RMSEA}=$ $.05 ; \mathrm{SRMR}=.05 . \Delta \chi^{2}$ tests comparing these models indicated that adding these direct effects did not improve the model significantly $\left.\left(\Delta \chi^{2}[3]=0.65, p=.88\right]\right)$. All the added direct paths were not significant whereas the indirect paths were significant. The indirect effect of the interaction between clarity and coherence of integration policies on personal attitudes toward interculturalism was significant, $b=0.09,95 \%$ CI $[0.02,0.16], p=.015$. The indirect effect of the perceived cultural norm of interculturalism on well-being was significant, $b=0.13,95 \%$ CI $[0.05,0.25], p<.001$. Finally, the indirect effect of perceived cultural norm of interculturalism on prejudice was also significant, $b=-0.62,95 \%$ CI $[-0.84$, $-0.46], p<.001$. In sum, the data in Québec is quite consistent with the model represented in Figure 1.

In France, as there are two distinct components (historical and new secularism) we added six direct paths to the model: 1) interaction between clarity and coherence of integration policies on personal attitudes toward historical secularism, 2) interaction between 
clarity and coherence of integration policies on personal attitudes toward new secularism, 3) perceived cultural norm of historical secularism on well-being, 4) perceived cultural norm of new secularism on well-being, 5) perceived cultural norm of historical secularism on prejudice, and finally 6) perceived cultural norm of new secularism on prejudice. The overall fit indices of this model were similar to our proposed and final model: $\chi^{2}(500)=2208.67, p$ $<.001 ; \mathrm{CFI}=.90 ; \mathrm{RMSEA}=.06 ; \mathrm{SRMR}=.06$. However, $\Delta \chi^{2}$ tests comparing these models indicated that adding the direct effects improved the model significantly $\left(\Delta \chi^{2}[11]=176.96\right.$, $p<.001)$. This might be explained by the fact that three out of six of the added direct paths were significant (i.e., the last three). The results showing direct effect of the perceived cultural norm on prejudice are in line with past research (see Guimond et al., 2013).

The indirect effect of the interaction between clarity and coherence of integration policies on personal attitudes toward historical secularism was significant, $b=0.0495 \% \mathrm{CI}$ $[0.00,0.09], p=.045$. The indirect effect of the interaction between clarity and coherence of integration policies on personal attitudes toward new secularism was also significant, $b=$ $0.13,95 \%$ CI $[0.06,0.19], p=.001$. The indirect effect of perceived cultural norm of historical secularism on well-being was not significant, $b=0.03,95 \%$ CI [-0.06, 0.08], $p=$ .566. The indirect effect of perceived cultural norm of new secularism on well-being was marginally significant, $b=1.05,95 \%$ CI [-10.48, 0.04], $p=.075$. The indirect effect of perceived cultural norm of historical secularism on prejudice was significant, $b=-0.66,95 \%$ CI [-0.85, -0.51], $p<.001$. Finally, the indirect effect of perceived cultural norm of new secularism on prejudice was significant, $b=1.48,95 \%$ CI $[0.16,16.86], p=.023$. In sum, there is strong evidence for our predictive model in both countries. Exploratory analyses suggest that, depending on the national context, adding direct paths from the perceived norm component of the model may improve model fit.

\section{Testing an Alternative Model}


To further test the causal order of the variables and also to test if the proposed models best fit the data, we examined an alternative model positing that the interaction between clarity and coherence of integration policies would be predicted by the perceived cultural norms. This model, both for Québec and France, showed lower fit indices [Québec: the $\chi^{2}$ was not available due to a negative variance; $\mathrm{CFI}=.89 ; \mathrm{RMSEA}=.07, \mathrm{SRMR}=.11$; France: $\left.\chi^{2}(509)=3557.021, p<.001 ; \mathrm{CFI}=.83 ; \mathrm{RMSEA}=.08 ; \mathrm{SRMR}=.12\right]$.

\section{Exploring the Unique Role of Interculturalism}

In order to further distinguish the unique role of interculturalism from multiculturalism, we conducted three additional hierarchical multiple regressions in Québec, one for each of the dependent variables (i.e., prejudice, life satisfaction, subjective authenticdurable happiness). Specifically, in these regressions, we entered personal attitudes toward multiculturalism as a predictor in the first step and personal attitudes toward interculturalism as a predictor in the second step. Personal attitudes toward multiculturalism was negatively associated with prejudice in the first step $(\beta=-0.51, p<.001)$ as well as in the second step $(\beta$ $=-0.27, p<.001$ ), while personal attitudes toward interculturalism was negatively linked to prejudice $(\beta=-0.42, p<.001)$ in the second step. The pattern of results was slightly different with well-being variables. While personal attitudes toward multiculturalism was positively associated with life satisfaction $(\beta=0.11, p=.001)$ and subjective authentic-durable happiness $(\beta=0.10, p=.007)$ in the first steps of the regressions, only personal attitudes toward interculturalism was positively linked with life satisfaction $(\beta=0.15, p<.001)$ and subjective authentic-durable happiness $(\beta=0.15, p<.001)$ in the second steps of the regressions. In sum, personal attitudes toward interculturalism were related to less prejudice, and more well-being, over and above the influence of personal attitudes toward multiculturalism.

\section{Discussion}


There has been a growing appreciation of the fact that national integration policies can shape individuals' attitudes toward immigrants (Green et al., 2019; Guimond et al., 2013; Igarashi, 2019; Schlueter et al., 2013). In the present research, we tested our current understanding of how this may come about, providing, in the process, significant advances over past research in three critical areas: 1) the nature of integration policies that exist in different countries, 2) the kind of impact that these integration policies can have on the general population, and 3) through what psychological processes a given integration policy can impact the prejudice and well-being of the population. A focus on the impact of national policies may be of considerable importance because it implies that the behaviour of millions of people in a country is at stake. We will discuss each of these three critical points in turn.

\section{The Nature of Interculturalism and Secularism as Integration Policies}

The significance of the results of the present research must be measured in light of what is currently known in the field. According to Whitley and Webster's (2018) metaanalytic review, past research has focused on three intergroup ideologies, assimilation, multiculturalism, and colorblindness, without considering their normative dimensions and often without taking into account the national context. The current evidence speaks first to the fact that in different societies, there are integration policies that can lead to the development of intergroup ideologies that are distinct from assimilation, multiculturalism, or colorblindness. For example, our results show that the population of Québec values interculturalism significantly more than the population of France whereas the French value secularism significantly more than Quebecers. These results can be explained by the fact that these two countries have distinct integration policies. Of course, this does not mean that “secularism" or "multiculturalism" are not important in Québec. Our findings indicate that these concepts are perceived as positively as interculturalism by the Québec population. 


\section{The Impact of Integration Policies on Majority Group Members}

These considerations are important when dealing with the second critical point noted above concerning the kind of impact that a given integration policy can have on the population. In the present research, we have considered prejudice against immigrants and psychological well-being as two possible outcomes. We find that interculturalism is clearly associated with less prejudice, consistent with the hierarchy-attenuating nature of the policy, and also with more psychological well-being. This is probably the first concrete evidence that has a bearing on the value of interculturalism as an integration policy in a society that has promoted such a policy in the last several years. Interculturalism was also proposed as a policy for the European Union to replace multiculturalism, without any evidence as to its potential impact on intergroup relations (Kymlicka, 2012). Our findings suggest that interculturalism may foster social cohesion and decrease intergroup conflicts. Hostile attitudes toward newcomers in a country are an important sign of intergroup divisions that threaten cohesion. Because interculturalism, as measured here, is clearly related to more positive attitudes toward immigrants and greater well-being among the general population, it is a policy that can be expected to have a generally positive impact on intergroup relations. Indeed, considering the criticisms emerging in some quarters about multiculturalism, such as the fact that it may represent a threat for majority group members who can feel excluded by such a policy (Verkuyten, 2014; Whitley \& Webster, 2018), our findings indicate that interculturalism represents a major and credible alternative that speaks directly to such issues. As indicated in the introduction and as captured by our measures of attitudes and perceived norms, interculturalism implies, contrary to multiculturalism, the recognition of the culture and language of the majority group. Our exploratory results on the unique role of interculturalism further support this claim by suggesting that a policy of interculturalism may represent the best of both worlds: a policy that reduces prejudice against immigrants and 
increases well-being without generating, among majority group members, feelings of cultural threat.

The fact that national integration policies have an important bearing on intergroup relations is further supported by our results obtained in the French national context. We find that historical secularism in France relates to a significant decrease in prejudice whereas, expectedly, the reverse is observed when new secularism is taken into account. This is consistent with much recent research conducted in France (Nugier et al., 2016; Roebroeck \& Guimond, 2016, 2018; Troian et al., 2018). However, because this is found within a representative sample of the mainstream French population, these findings raise serious questions about advocates of this new secularism that are now emerging, not only from the extreme right but also among people from the left and the moderate right. There is no evidence to support the claim that this new secularism in France connects interchangeably with the historical meaning of secularism that was tied to equality and freedom of conscience. These results, although of a correlational nature, nevertheless provide considerable insights into why a national policy can improve intergroup relations. The policy of secularism in France is arguably very different from the policy of interculturalism in Québec. Yet, as suggested by social dominance theory (Sidanius \& Pratto, 2012), an important feature of a policy that predicts the kind of impact it can have on intergroup relations, is whether it is hierarchy-enhancing or -attenuating. We have argued that interculturalism and historical secularism are both hierarchy-attenuating policies that should improve intergroup relations, in contrast to new secularism in France that is hierarchy-enhancing. The findings are strongly supportive of this reasoning not only with regards to prejudice but also concerning wellbeing.

The results concerning psychological well-being are especially notable because this is the first time to our knowledge that a direct link between personal support for a national 
integration policy and well-being is documented. So far, well-being has been studied in acculturation research among immigrants and minority group members but rarely among samples of majority group members. Past research has showed that when immigrants integrated their multiple identities or culture, well-being ensued (Berry et al., 2006; Carpentier \& de la Sablonnière, 2013; Yampolsky et al., 2016). Similarly, there is much evidence documenting the health hazards associated with prejudice and discrimination among ethnic minorities (Verkuyten, 2014). Such evidence has begun to emerge also when considering national integration policies. For example, Malmusi (2015) reported that across 11 European countries, those having an "exclusionist" integration policy are those where immigrants report the worse self-rated health. In contrast, much less is known about majority group members. As indicated in the introduction, the study of Jackson and Doerschler (2016) found that "Majority group members appear to be consistently more satisfied with life in states that have taken the turn toward inclusive policies that seem to promote multiculturalism" (p. 14). However, this finding is based on a single-item measure of satisfaction with life. Our results, using two reliable scales measuring psychological wellbeing in two different states, provide much needed support for this perspective.

In pointing to the fact that there are important positive relations between personal attitudes toward hierarchy-attenuating policies (positive personal attitudes toward interculturalism in Québec and historical secularism in France) and psychological and emotional well-being, the present research provides a significant advance in interest for researchers and policy makers. The fact that in terms of well-being, similar results are obtained in two different national samples and concerning two distinct integration policies, underscores the reliability of the phenomenon. In France, we also show that perceived cultural norms and personal attitudes relating to a policy dimension that does not reduce prejudice, such as new secularism, does not relate to greater psychological well-being. This 
result provides evidence that it is not any kind of policy that can improve the well-being of group members.

\section{Testing a Model Explaining the Effects of National Integration Policies}

Finally, the third and most important contribution of the present research concerns the question of how and why the existence of a given integration policy in a society can shape the psychological attitudes of the population at large. We argued that there are two key factors to consider for a better understanding of the impact of national integration policies on the general population: the perceived clarity and the perceived coherence of these integration policies. While perceived clarity is defined as the extent to which a national policy is judged as providing enough information to understand its goals and implication, perceived coherence is defined as the extent to which a national policy fits the general ideology of the country. We presented an integrative predictive model (Figure 1) and proposed that perceived clarity and perceived coherence of a government's integration policy interact to predict perceived cultural norms which subsequently predict individuals' personal attitudes toward cultural norms, which then predict individuals' prejudice and well-being. A comprehensive test of this model was presented using representative samples of the mainstream population from two distinct national settings, one in Europe and one in North America. In France, the model was tested with historical and new secularism and in Québec with interculturalism (for perceived cultural norms and for personal attitudes toward cultural norms).

Regardless of settings, the results of SEM yielded evidence of an adequate fit of the theoretical model to the data, suggesting that government policies at the national level can indeed create a context that shapes well-being and that either fosters the expression of ethnic prejudice or reduces it. In Québec and in France, the perceived clarity and coherence of the government's action regarding the integration of immigrants were assessed in the same way, with identical measures, and without referring specifically to interculturalism or secularism. 
Nevertheless, in Québec, we found that these two factors interact to determine the perceived interculturalism norm whereas in France, they interact in the same manner to determine the perceived historical secularism norm. In Québec, participants perceived that the people are supportive of the principle of interculturalism especially when they perceive that the government policy is both clear and coherent. They perceived the lowest level of support for interculturalism when the government policy is perceived as high in clarity but low in coherence. The exact same findings emerged in France in terms of the historical secularism norm, that is in terms of the perceived level of support that the population of France displays when it comes to the principle of historical secularism. However, the pattern of the interaction was different with new secularism in France where the perceived cultural norm of new secularism was the highest when clarity was low. These results confirm that there is an important distinction between the two norms of secularism in France (Roebroeck \& Guimond, 2016). The content of these two norms is different and more problematic in the case of new secularism. Consequently, it may be that such a policy will be perceived as largely supported by others only when it is ambiguous and not well understood by the people.

When testing an alternative model positing the reverse causal order, with the perceived norms predicting the perceived clarity and coherence of integration policies, we found lower fit indices in Québec and in France. These results confirm the importance of using theoretical and empirical work around the concepts of clarity and coherence (e.g., Taylor \& de la Sablonnière, 2014) to understand the impact of national integration policies.

Subsequent steps in the model were also strikingly confirmed. When participants in Québec perceive a strong interculturalism norm, they are more likely to support interculturalism themselves personally, and the more they support interculturalism, the less hostile they are toward immigrants and the better is their psychological well-being. Similarly in France, when participants perceive a strong norm of historical secularism, they are more 
likely to support historical secularism personally, and the more they support this policy, the less hostile they are toward immigrants and the better is their psychological well-being. Thus, the findings observed in Québec were replicated in France, despite the fact that the French policy is completely different, underlining the robustness of the phenomenon. Finally, the fact that the content of the integration policy matters, is illustrated in a number of ways. We find that when French people are led to personally support new secularism, they express higher levels of prejudice against immigrants, not lower levels. Similarly, there is evidence in France, but not in Québec, that model fit can be improved by adding direct paths from the perceived cultural norms to prejudice. In France, the perceived norms of historical secularism and new secularism relate directly to prejudice, and via their effects on personal attitudes toward historical and new secularism, respectively. This is consistent with past research on assimilation and multiculturalism and reinforce the claim that targeting group norms can be effective in changing intergroup attitudes (Guimond et al., 2013).

\section{Limitations and Future Research}

As with any study, the findings reported here do not allow us to reach definite conclusions. Given the correlational nature of our data and the fact that there is only a portion of the variance explained by our overall models, there is a need for further research especially of an experimental nature. Previous experimental work has found causal effects of multiculturalism and colorblindness on stereotyping and prejudice (Wolsko, Park, Judd, \& Wittenbrink, 2000). The present study certainly offers a sound basis for further development in this direction by testing the effects of interculturalism and secularism (for initial evidence, see Anier et al., 2018; Scott \& Safdar, 2017). Ideally, these experiments should be conducted by controlling for national context effects, something that is still lacking in the literature (see Guimond et al., 2014). The perceived cultural norm subscales could be used as a basis for developing experimental manipulation depending on the research contexts. Similarly, 
longitudinal studies are needed to improve our understanding of the actual process by which cultural norms are promoted, and the implications for how people develop intergroup attitudes in addition to well-being. Our findings do not contradict research that aims at examining individual factors such as RWA or SDO (for supportive evidence, see Guimond et al., 2013). However, our research identifies the social context as a primary player in terms of understanding the reasons why one becomes prejudiced and develops discriminative attitudes in the long term. Following the social projection theory (Robbins \& Krueger, 2005), it is possible to argue that the individuals' own attitudes are projected onto their perceptions of the attitude of others. In this case, individuals might project their own attitudes about a given integration policy (personal attitudes) to their perception of the attitude of others toward this policy (perceived cultural norms). Although this may occur in some contexts, the present research and previous comparative research on multiculturalism and assimilation did not support the view that perceived cultural norms are shaped by personal attitudes (see Guimond et al., 2013, 2015).

At a methodological level, the fact that we used two large representative samples of the mainstream population is also of importance to the study of prejudice and well-being. It was important to have group members other than students because it is well-known that university students have less prejudice as compared to the general population (Guimond et al., 2015; Henrich, Heine, \& Norenzayan, 2010; Henry, 2008). For example, the French sample used here included a sizable number of people who are from the extreme-right and display ethnic prejudice in an explicit manner. Although this is a question for further research, the findings so far suggest that perceived norms and personal attitudes regarding national integration policies play a similar role in the explanation of prejudice regardless of political orientation (see Roebreock \& Guimond, 2018). This may seem surprising and certainly warrants more scrutiny. However, one explanation is that even groups that differ 
strongly in their personal attitudes toward multiculturalism and assimilation were found to share the same perceived cultural norm as it relates to assimilation and multiculturalism, such as French-speaking and English-speaking people in Québec (Pelletier-Dumas et al., 2017) or the extreme-right and the extreme-left wing in France (Guimond et al., 2015).

Finally, our findings have several practical implications. Our work aims to sensitize national governments to better communicate their integration policies in order to influence individuals' attitudes toward these policies. Our findings suggest that governments should emphasize the clarity and coherence of their policies to generate a greater adherence when national integration policies are hierarchy-attenuating. By contrast, the international community might keep an open eye to the clarity and coherence of integration policies in countries where hierarchy-enhancing national integration policies are promoted. The rise of populism in the world which promotes simple messages that are clear and coherent, may contribute to how the cultural norms are perceived.

Our research should also sensitize decision makers in general (i.e., in public and private institutions): By clearly defining and explaining a decision, and by framing it as consistent with existing norms, these norms and policies can influence the reaction of individuals toward a specific decision. In doing so, governments could enhance the population's well-being (if integration policies are promoted) which is an important public health concern. In the long term, ensuring that the policies of historical secularism (France) and interculturalism (Québec) are clear and more coherent, will surely pay off in terms of reducing prejudice and increasing well-being. It would be important to test if our findings can be replicated in countries with different norms and policies. The evidence presented here argues that the theoretical principles underlying our results should be valid in many other contexts. 


\section{References}

Akan, M. (2009). Laïcité and multiculturalism: The Stasi Report in context. The British Journal of Sociology, 60, 237-256. doi: 10.1111/j.1468-4446.2009.01229.x

Altemeyer, B. (1998). The other "Authoritarian Personality”. Advances in Experimental Social Psychology, 30, 47-92. doi: 10.1016/S0065-2601(08)60382-2

Amiot, C. E., de la Sablonnière, R., Terry, D. J., \& Smith, J. R. (2007). Development and integration of social identities in the self: Toward a cognitive-developmental model. Personality and Social Psychology Review, 11, 364-388. doi: $10.1177 / 1088868307304091$

Anier, N., Badea, C., Berthon, M., \& Guimond, S. (2018). Perceived acculturation preferences of minority groups and intergroup discrimination: When culture-specific intergroup norms matter. Journal of Applied Social Psychology, 48, 506-518. doi: $10.1111 /$ jasp. 12530

Baerger, D. R., \& McAdams, D. P. (1999). Life story coherence and its relation to psychological well-being. Narrative Inquiry, 9, 69-96. doi : 10.1075/ni.9.1.05bae

Baubérot, J. (2012). La Laïcité falsifiée [Falsified laïcité]. Paris, France: La Découverte.

Baumeister, R. F., \& Leary, M. R. (1995). The need to belong: Desire for interpersonal attachments as a fundamental human motivation. Psychological Bulletin, 117, 497-529. doi: 10.1037/0033-2909.117.3.497

Benet-Martinez, V., \& Haritatos, J. (2005). Bicultural Identity Integration (BII): Components and psychosocial antecedents. Journal of Personality, 73, 1015-1050. doi: $10.1111 / \mathrm{j} .1467-6494.2005 .00337 . \mathrm{x}$

Berry, J. W. (1990). Psychology of acculturation. In N. R. Goldberger \& J. B. Veroff (Eds.), The culture and psychology reader (pp. 457-488). New York, NY: New York 
University Press. (Reprinted from Nebraska symposium on motivation: Cross-cultural perspectives, J. J. Berman, [Ed.], 1989, Lincoln, NE: University of Nebraska Press).

Berry, J. W., \& Kalin, R. (1995). Multicultural and ethnic attitudes in Canada: An overview of the 1991 National Survey. Canadian Journal of Behavioural Science, 27, 301-320.

doi: 10.1037/0008-400X.27.3.301

Berry, J. W., Kalin, R., \& Taylor, D. M. (1977). Attitudes à l'égard du Multiculturalisme et des groupes ethniques au Canada [Attitudes towards multiculturalism and ethnic groups in Canada]. Ottawa, Canada: Supply and Services Canada.

Berry, J. W., Phinney, J. S., Sam, D. L., \& Vedder, P. (2006). Immigrant youth: Acculturation, identity, and adaptation. Applied psychology, 55, 303-332. doi : 10.1111/j.1464-0597.2006.00256.x

Blais, M. R., Vallerand, R. J., Pelletier, L. G., \& Brière, N. M. (1989). L'échelle de satisfaction de vie: Validation canadienne-française du "Satisfaction with Life Scale" [Satisfaction with Life Scale : A French-Canadian validation of the "Satisfaction with Life Scale"]. Revue Canadienne de Sciences Comportementales, 21, 210-223. doi : $10.1037 / \mathrm{h} 0079854$

Blanchard, F. A., Crandall, C. S., Brigham, J. C., \& Vaughn, L. A. (1994). Condemning and condoning racism: A social context approach to interracial settings. Journal of Applied Psychology, 79, 993-997. doi: 10.1037/0021-9010.79.6.993

Bleich, E. (2001). The French model: Color-blind integration. In J. D. Skrentny (Ed.), Color lines: Affirmative action, immigration, and civil rights options for America, (pp. 270296). Chicago, IL: University of Chicago Press.

Bouchard, G. (2011). Qu'est-ce que l'interculturalisme ? / What is Interculturalism? McGill Law Journal, 56, 395-468. doi:10.7202/1002371ar

Bouchard, G. (2012). L’interculturalisme: Un point de vue québécois [Interculturalism : A 
Quebecker's point of view]. Montréal, Canada: Boréal.

Bouchard, G. \& Taylor, C. (2008). Building the future: A time for reconciliation. Report of the Consultation Commission on Accommodation Practices related to Cultural Differences. Quebec: Government of Quebec.

Campbell, J. D. (1990). Self-esteem and clarity of the self-concept. Journal of Personality and Social Psychology, 59, 538-549. doi: 10.1037/0022-3514.59.3.538

Carpentier, J., \& de la Sablonnière, R. (2013). Identity profiles and well-being of multicultural immigrants: the case of Canadian immigrants living in Quebec. Frontiers in Psychology, 4, 1-15. doi: 10.3389/fpsyg.2013.00080

Cole, M. S., Harris, S. G., \& Bernerth, J. B. (2006). Exploring the implications of vision, appropriateness, and execution of organizational change. Leadership \& Organization, 27, 352-367. doi: 10.1108/01437730610677963

Crandall, C. S., Eshleman, A., \& O'Brien, L. (2002). Social norms and the expression and suppression of prejudice: The struggle for internalization. Journal of Personality and Social Psychology, 82, 359-378. doi: 10.1037//0022-3514.82.3.359

Dambrun, M., \& Guimond, S. (2001). La théorie de la privation relative et l'hostilité envers les Nord-Africains [The theory of relative deprivation and hostility towards North Africans]. Revue Internationale de Psychologie Sociale, 14, 57-89.

Dambrun, M., Ricard, M., Després, G., Drelon, E., Gibelon, E., ... Michaux, O. (2012). Measuring happiness: From fluctuating happiness to authentic-durable happiness. Frontiers in Psychology, 3, 1-11. doi: 10.3389/fpsyg.2012.00016

Diener, E., Diener, M., \& Diener, C. (1995). Factors predicting the subjective well-being of nations. Journal of Personality and Social Psychology, 69, 851-864. doi: $10.1037 / 0022-3514.69 .5 .851$ 
Diener, E., Emmons, R. A., Larsen, R. J., \& Griffin, S. (1985). The Satisfaction With Life Scale. Journal of Personality Assessment, 49, 71-75. doi: 10.1207/s15327752jpa4901_13

Diener, E., \& Ryan, K. (2009). Subjective well-being: A general overview. South African Journal of Psychology, 39, 391-406. doi: 10.1177/008124630903900402

Festinger, L. (1950) Informal social communication. Psychological Review, 57, 271-282. doi: $10.1037 / \mathrm{h} 0056932$

Festinger, L. (1957). A theory of cognitive dissonance. Evanston, IL: Row, Peterson.

Gagnon A. G., \& Iacovino, R. (2007). Federalism, citizenship, and Quebec: Debating multinationalism. Toronto, Canada: University of Toronto Press.

Guimond, S., Crisp, R. J., De Oliveira, P., Kamiejski, R., Kteily, N., Kuepper, B., . . Zick, A. (2013). Diversity policy, social dominance, and intergroup relations: Predicting prejudice in changing social and political contexts. Journal of Personality and Social Psychology, 104, 941-958. doi: 10.1037/a0032069

Guimond, S., Dambrun, M., Michinov, N., \& Duarte, S. (2003). Does social dominance generate prejudice? Integrating individual and contextual determinants of intergroup cognitions. Journal of Personality and Social Psychology, 84, 697-721. doi: $10.1037 / 0022-3514.84 .4 .697$

Guimond, S., de la Sablonnière, R., \& Nugier, A. (2014). Living in a multicultural world: Intergroup ideologies and the societal context of intergroup relations. European Review of Social Psychology, 25, 142-188. doi: 10.1080/10463283.2014.957578

Guimond, S., Streith, M., \& Roebroeck, E. (2015). Les représentations du multiculturalisme en France: Décalage singulier entre l'individuel et le collectif [Representations of multiculturalism in France : Singular discrepancy between individual and the group]. Social Science Information, 54, 52-77. doi: 10.1177/0539018414554826 
Green, E. G. T., Visintin E. P., Sarrasin O., \& Hewstone M. (2019). When integration policies shape the impact of intergroup contact on threat perceptions: A multilevel study across 20 European countries. Journal of Ethnic and Migration Studies, 1-18. doi: 10.1080/1369183X.2018.1550159

Henrich, J., Heine, S. J., \& Norenzayan, A. (2010). The weirdest people in the world? Behavioral and Brain Sciences, 33, 61-135. doi: 10.1017/S0140525X0999152X.

Henry, P. J. (2008). College sophomores in the laboratory redux: Influences of a narrow data base on social psychology's view of the nature of prejudice. Psychological Inquiry, 19, 49-71. doi: 10.1080/10478400802049936

Igarashi, A. (2019). Till multiculturalism do us part: Multicultural policies and the national identification of immigrants in European countries. Social Science Research, 77, 88100. doi: 10.1016/j.ssresearch.2018.10.005

Jackson, P. I., \& Doerschler, P. (2016). How safe do majority group members, ethnic minorities and Muslims feel in multicultural European societies? Democracy and Security, 12, 247-277. doi: 10.1080/17419166.2016.1213165

Kamiejski, R., Guimond, S., De Oliveira, P., Er-Rafiy, A., \& Brauer, M. (2012). Le modèle républicain d'intégration: Implications pour la psychologie des relations entre groupes [The republican model of integration: The implications for the psychology of intergroup relations]. L'Année Psychologique, 112, 49-83. doi: 10.4074/ S0003503312001030

Kleinlogel, E. P., Nugier, A., Pelletier-Dumas, M., de la Sablonnière, R., \& Guimond, S. (2019). Why do people come to support a highly controversial law? Manipulating the clarity and coherence of a law can shape individuals' perception and approval. Manuscript submitted for publication. 
Kline, R. B., (2016). Principles and practice of structural equation modeling (4th ed.). New York, NY: Guilford Press.

Koopmans, R., Statham, P., Giugni, M., \& Passy, F. (2005). Contested citizenship: Immigration and cultural diversity in Europe. Minneapolis, MN: University of Minnesota Press.

Kymlicka, W. (2012). Comment on Meer and Modood. Journal of Intercultural Studies, 33, 211-216. doi: 10.1080/07256868.2012.649528

Levin, S., Matthews, M., Guimond, S., Sidanius, J., Pratto, F., Kteily, N., ... \& Dover, T. (2012). Assimilation, multiculturalism, and colorblindness: Mediated and moderated relationships between social dominance orientation and prejudice. Journal of Experimental Social Psychology, 48, 207-212. doi: 10.1016/j.jesp.2011.06.019

Little, T. D., Cunningham, W. A., Shahar, G., \& Widaman, K. F. (2002). To parcel or not to parcel: Exploring the question, weighing the merits. Structural Equation Modeling: A Multidisciplinary Journal, 9, 151-173. doi: 10.1207/S15328007SEM0902_1

Malmusi, D. (2015). Immigrants' health and health inequality by type of integration policies in European countries. European Journal of Public Health, 25, 293-299. doi: 10.1093/eurpub/cku156

Matsunaga, M. (2008). Item parceling in structural equation modeling: A primer. Communication Methods and Measures, 2, 260-293. doi: $10.1080 / 19312450802458935$

McAdams, D. P. (1993). The stories we live by: Personal myths and the making of the self. New York, NY: Guilford Press.

Modood, T., \& Meer, N. (2012). Interculturalism, Multiculturalism or Both? Political Insight, 3, 30-33. doi: 10.1111/j.2041-9066.2012.00097.x 
Moghaddam, F. M., Taylor, D. M., \& Wright, S. C. (1993). Social psychology in crosscultural perspective. New York, NY: W.H. Freeman.

Nugier, A., Oppin, M., Cohu, M., Kamiejski, R., Roebroeck, E., \& Guimond, S. (2016). «Nouvelle laïcité» en France et pression normative envers les minorités musulmanes [Secularism in France and normative pressure against muslim minorities]. International Review of Social Psychology, 29, 15-30. doi: 10.5334/irsp.11

Pelletier-Dumas, M., de la Sablonnière, R., \& Guimond, S. (2017). The role of assimilation and multiculturalism for the relation between social dominance orientation and prejudice: The Case of anglophones and francophones in Québec. Journal of CrossCultural Psychology, 48, 874-891. doi: 10.1177/0022022117706414.

Portelinha, I., \& Elcheroth, G. (2016). From marginal to mainstream: The role of perceived social norms in the rise of a far-right movement. European Journal of Social Psychology, 46, 661-671. doi: 10.1002/ejsp.2224

Pratto, F., Sidanius, J., \& Levin, S. (2006). Social dominance theory and the dynamics of intergroup relations: Taking stock and looking forward. European Review of Social Psychology, 17, 271-320. doi: 10.1080/10463280601055772

Pratto, F., Sidanius, J., Stallworth, L. M., \& Malle, B. F. (1994). Social dominance orientation: A personality variable predicting social and political attitudes. Journal of Personality and Social Psychology, 67, 741-763. doi: 10.1037/0022-3514.67.4.741

Robbins, J. M., \& Krueger, J. I. (2005). Social projection to ingroups and outgroups: A review and meta-analysis. Personality and Social Psychology Review, 9, 32-47. doi: 10.1207/s15327957pspr0901_3

Rocher, G., Labelle, M., Field, A.-M., \& Icart, J.-C. (2007). Le concept d'interculturalisme en contexte Québécois: généalogie d'un néologisme [The concept of interculturalism in the context of Québec: Genealogy of a neologism]. Rapport présenté à la Commission 
de consultation sur les pratiques d'accommodement reliées aux différences culturelles (CCPARDC).

Rocher, G., \& White B. W. (2014). L’interculturalisme québécois en contexte multiculturel canadien [Québec's intercultiralism in the canadian mulicultural context]. Institut de Recherches en Politiques Publiques, 49, 1-48.

Roebroeck, E., \& Guimond, S. (2015). Schooling, citizen-making, and anti-immigrant prejudice in France. Journal of Social and Political Psychology, 3, 20-42. doi: 10.5964/jspp.v3i2.391

Roebroeck, E., \& Guimond, S. (2016). Pour une psychologie sociale de la laïcité : Identification et mesure de deux conceptions distinctes de la laïcité [For a social psychology of laïcité: Identification and measure of two distinct conceptions of laïcité]. L'Année Psychologique, 116, 489-518. doi: 10.4074/S0003503317000410

Roebroeck, E., \& Guimond, S. (2018). Intergroup threat, social dominance and the malleability of ideology: The importance of conceptual replication. European Journal of Social Psychology, 48, 134-149. doi: 10.1002/ejsp.2311

Rubin, M., \& Hewstone, M. (1998). Social identity theory's self-esteem hypothesis: A review and some suggestions for clarification. Personality and Social Psychology Review, 2, 40-62. doi: 10.1207/s15327957pspr0201_3

Schachner, M. K., He, J., Heizmann, B., \& Van de Vijver, F. J. R. (2017). Acculturation and school adjustment of immigrant youth in six European countries: Findings from the programme for international student assessment (PISA). Frontiers in Psychology, 8, 111. doi: $10.3389 /$ fpsyg.2017.00649

Schlueter, E., Meuleman, B., \& Davidov, E. (2013). Immigrant integration policies and perceived group threat: A multilevel study of 27 Western and Eastern European countries. Social Science Research, 42, 670-682. doi: 10.1016/j.ssresearch.2012.12.001 
Schnapper, D. (2004). La République face aux communautarismes [The threat of communitarianism to the integrity of the Republic of France]. Etudes, 400, 177-188.

Scott, C., \& Safdar, S. (2017). Threat and prejudice against Syrian refugees in Canada: Assessing the moderating effects of multiculturalism, interculturalism, and assimilation. International Journal of Intercultural Relations, 60, 28-39. doi: 10.1016/j.ijintrel.2017.06.003

Sechrist, G. B., \& Stangor, C. (2001). Perceived consensus influences intergroup behavior and stereotype accessibility. Journal of Personality and Social Psychology, 80, 645654. doi: 10.1037//0022-3514.80.4.645

Sedikides, C., Gaertner, L., \& Toguchi, Y. (2003). Pancultural self-enhancement. Journal of Personality and Social Psychology, 84, 60-79. doi: 10.1037/0022-3514.84.1.60

Seymour, M. (2000). Quebec and Canada at the crossroads: A nation within a nation. Nations and Nationalism, 6, 227-255. doi: 10.1111/j.1354-5078.2000.00227.x

Sharma, S., \& Sharma, M. (2010). Self, social identity and psychological well-being. Psychological Studies, 55, 118-136. doi: 10.1007/s12646-010-0011-8

Sherif, M. (1953). The concept of reference groups in human relations. In M. Sherif \& M. O. Wilson (Eds.), Group relations at the crossroads (pp. 203-231). New York, NY: Harper.

Sidanius, J., \& Pratto, F. (2012). Social Dominance Theory. In P. A. M, van Lange, A. W. Kruglanski, \& Higgins, E. T. (Eds), Handbook of theories of social psychology (Vol. 2, pp. 418-439). Thousand Oaks, CA: SAGE publications.

Tajfel, H. (1982). Social identity and intergroup relations. Cambridge, UK: Cambridge University Press. 
Tankard, M. E., \& Paluck, E. L. (2017). The effect of a Supreme Court decision regarding gay marriage on social norms and personal attitudes. Psychological Science, 28, 13341344. doi: $10.1177 / 0956797617709594$

Taylor, D. M. (2002). The quest for identity: From minority groups to generation Xers. Westport, CT: Praeger.

Taylor, D. M., \& de la Sablonnière, R. (2014). Towards constructive change in aboriginal communities: A social psychology perspective. Montréal, Canada: McGill-Queen's University Press.

Tesser, A. (2003). Self-evaluation. In M. R. Leary \& J. P. Tangney (eds.), Handbook of self and identity (pp. 275-290). New York, NY: Guilford Press.

Thompson, T., \& Hepburn, J. (2003). Causal uncertainty, claimed and behavioural selfhandicapping. British Journal of Educational Psychology, 73, 247-266. doi: $10.1348 / 00070990360626967$

Troian, J., Bonetto, E., Varet, F., Barbier, M., \& Lo Monaco, G. (2018). The effect of social dominance on prejudice towards North-African minorities: Evidence for the role of social representation of Secularism as a legitimizing myth. International Journal of Intercultural Relations, 65, 6-104. doi: 10.1016/j.ijintrel.2018.05.002

Turner, J. C., Hogg, M. A., Oakes, P. J., Reicher, S. D., \& Wetherell, M. S. (1987). Rediscovering the social group: A self-categorization theory. Oxford, UK: Blackwell.

Turner, J. C., \& Reynolds, K. J. (2012). Self-categorization theory. In P. A. M. Van Lange, A. W. Kruklanski, \& E. Tory Higgins (Eds.), Handbook of theories of social psychology (Vol. 2, pp. 399-417). London, UK: Sage.

Usborne, E., \& Taylor, D. M. (2010). The role of cultural identity clarity for self-concept clarity, self-esteem, and subjective well-being. Personality and Social Psychology Bulletin, 36, 883-896. doi: 10.1177/0146167210372215 
Van de Vijver, F. J. R., Breugelmans, S. M., \& Schalk-Soekar, S. R. G. (2008).

Multiculturalism: Construct validity and stability. International Journal of Intercultural Relations, 32, 93-104. doi: 10.1016/j.ijintrel.2007.11.001

Verkuyten, M. (2014). Identity and cultural diversity: What social psychology can teach us. Hove, UK: Routledge.

Verkuyten, M. (2016). The integration paradox: Empirical evidence from the Netherlands. American Behavioral Scientist, 60, 583-596. doi: 10.1177/0002764216632838

Verkuyten, M., \& Hagendoorn, L. (1998). Prejudice and self-categorisation: The variable role of authoritarianism and in-group stereotypes. Personality and Social Psychology Bulletin, 24, 99-110. doi: 10.1177/0146167298241008

Whitley Jr., B. E., \& Webster, G. D. (2018). The relationships of intergroup ideologies to ethnic prejudice: A meta-analysis. Personality and Social Psychology Review. Advance online publication. doi: 10.1177/1088868318761423

Wolsko, C., Park, B., Judd, C. M., \& Wittenbrink, B. (2000). Framing interethnic ideology: Effects of multicultural and color-blind perspectives on judgments of groups and individuals. Journal of Personality and Social Psychology, 78, 635-654. doi:10.1037/0022-3514.78.4.635

Yampolsky, M. A., Amiot C. E., \& de la Sablonnière R. (2016). The Multicultural Identity Integration Scale (MULTIIS): Developing a comprehensive measure for configuring one's multiple cultural identities within the self. Cultural Diversity and Ethnic Minority Psychology, 22, 166-184. doi: 10.1037/cdp0000043

Zick, A., Küpper, B., \& Hövermann, A. (2011). Intolerance, prejudice and discrimination: A European report. Berlin, Germany: Friedrich Ebert Stiftung. 
Zitek, E. M., \& Hebl, M. R. (2007). The role of social norm clarity in the influenced expression of prejudice over time. Journal of Experimental Social Psychology, 43, 867-876. doi: 10.1016/j.jesp.2006.10.010 


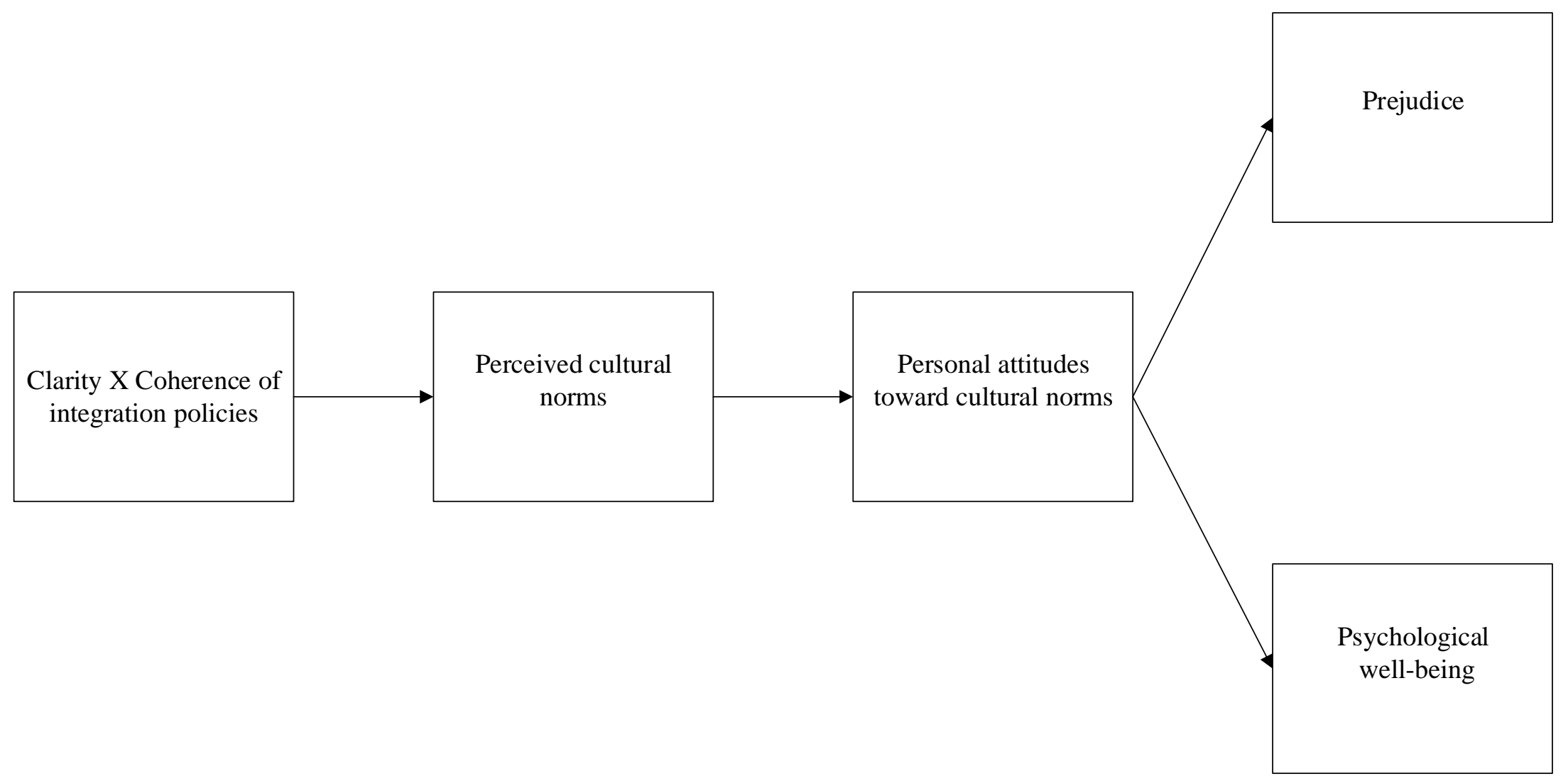

Figure 1. General predictive model. 


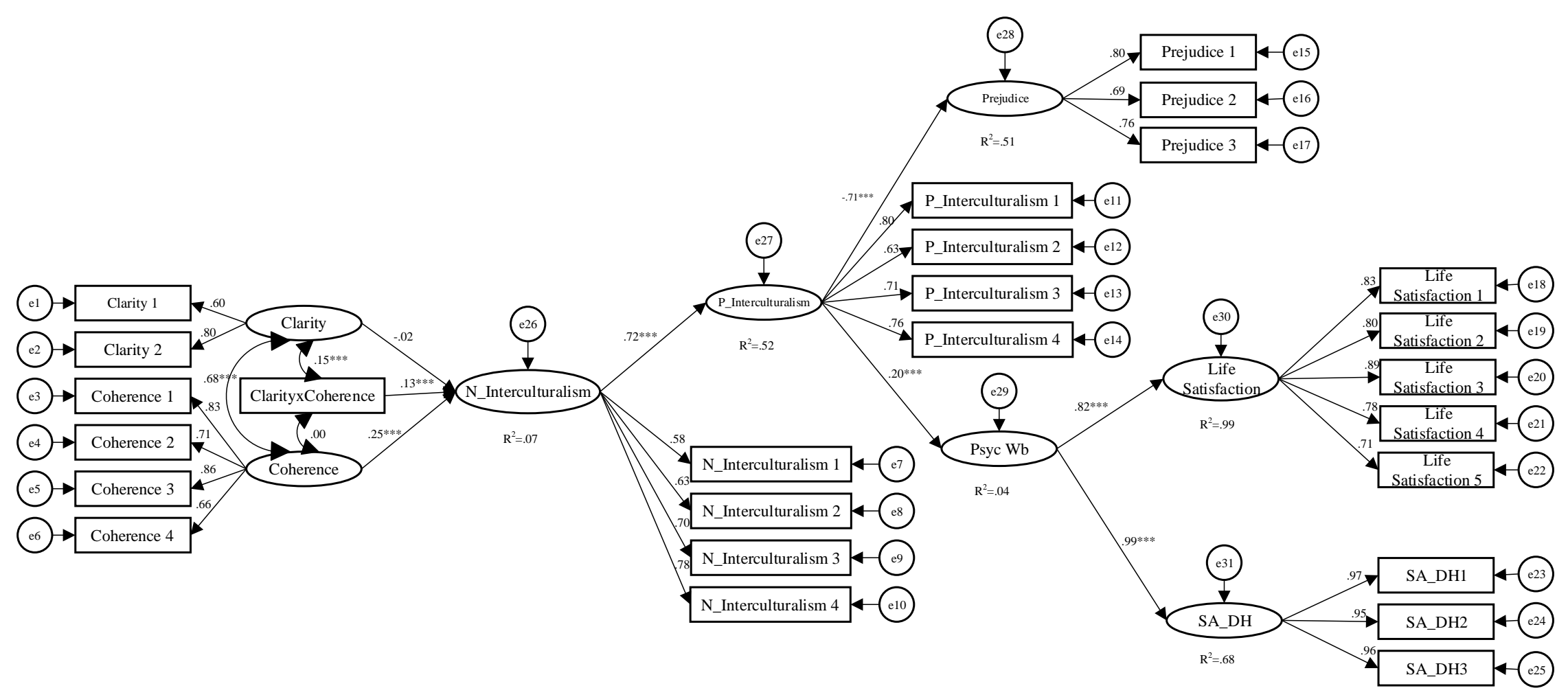

Figure 2. Interculturalism in Québec. Standardized effects are shown. $\mathrm{N}=$ Perceived cultural norms; $\mathrm{P}=$ Personal attitudes. ${ }^{*} p<.05, * * p<.01, * * * p<.001$. 


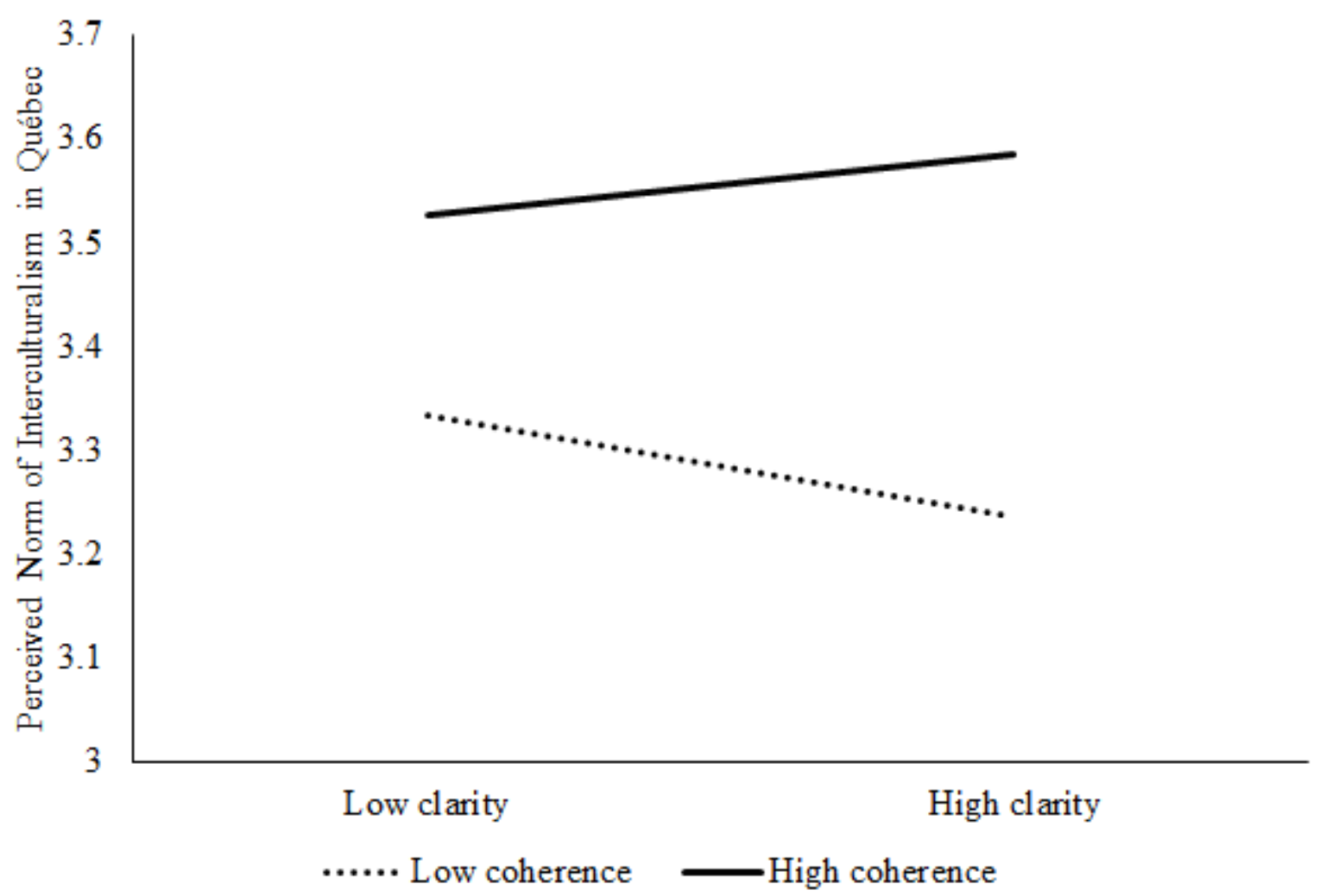

Figure 3. Interaction between clarity and coherence of integration policies on perceived norm of interculturalism (IC norm) in Québec. 


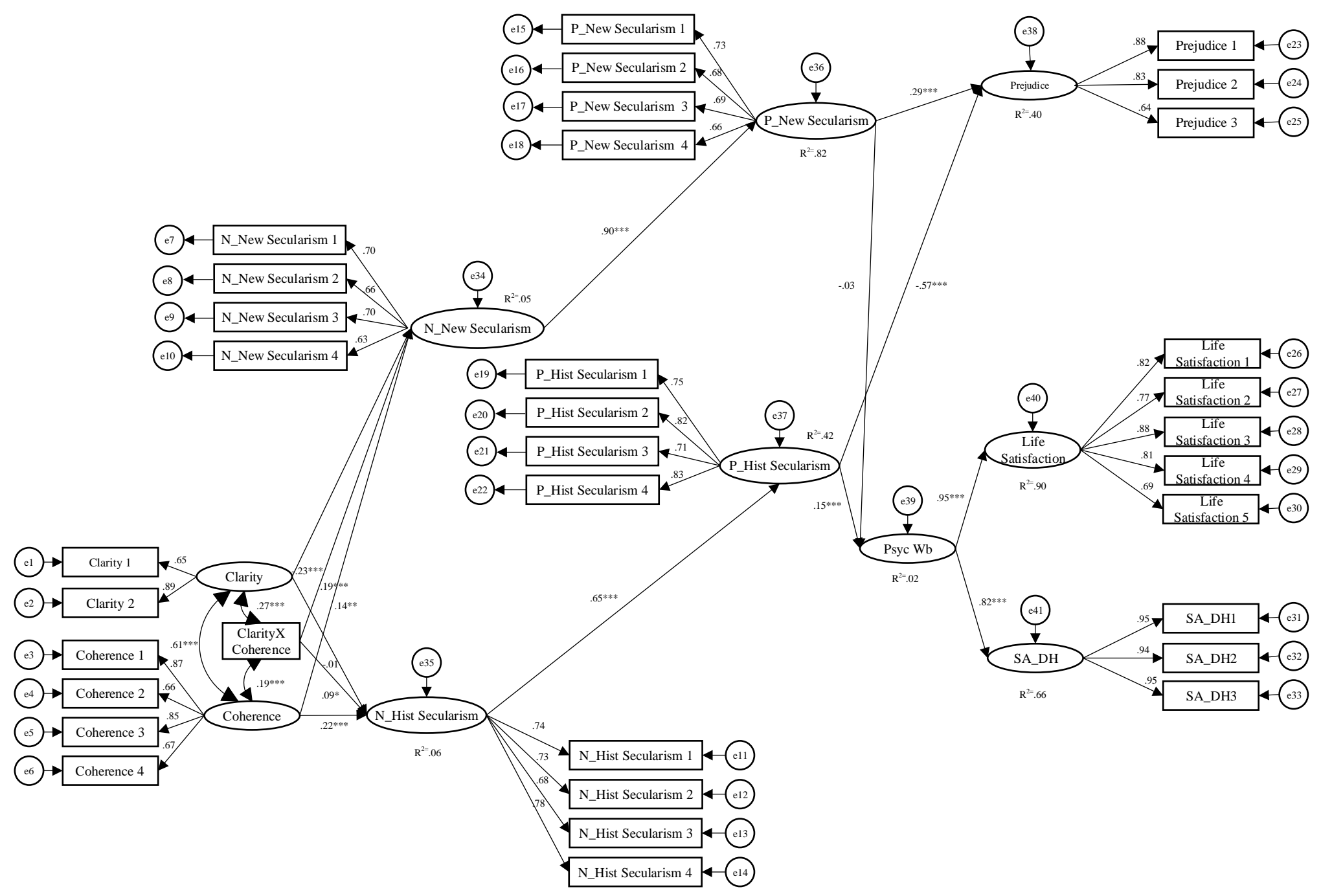

Figure 4. Historical and new secularism in France. Standardized effects are shown. $\mathrm{N}=$ Perceived cultural norms; $\mathrm{P}=\mathrm{Personal}$ attitudes. ${ }^{*} p$ $<.05, * * p<.01, * * * p<.001$. 


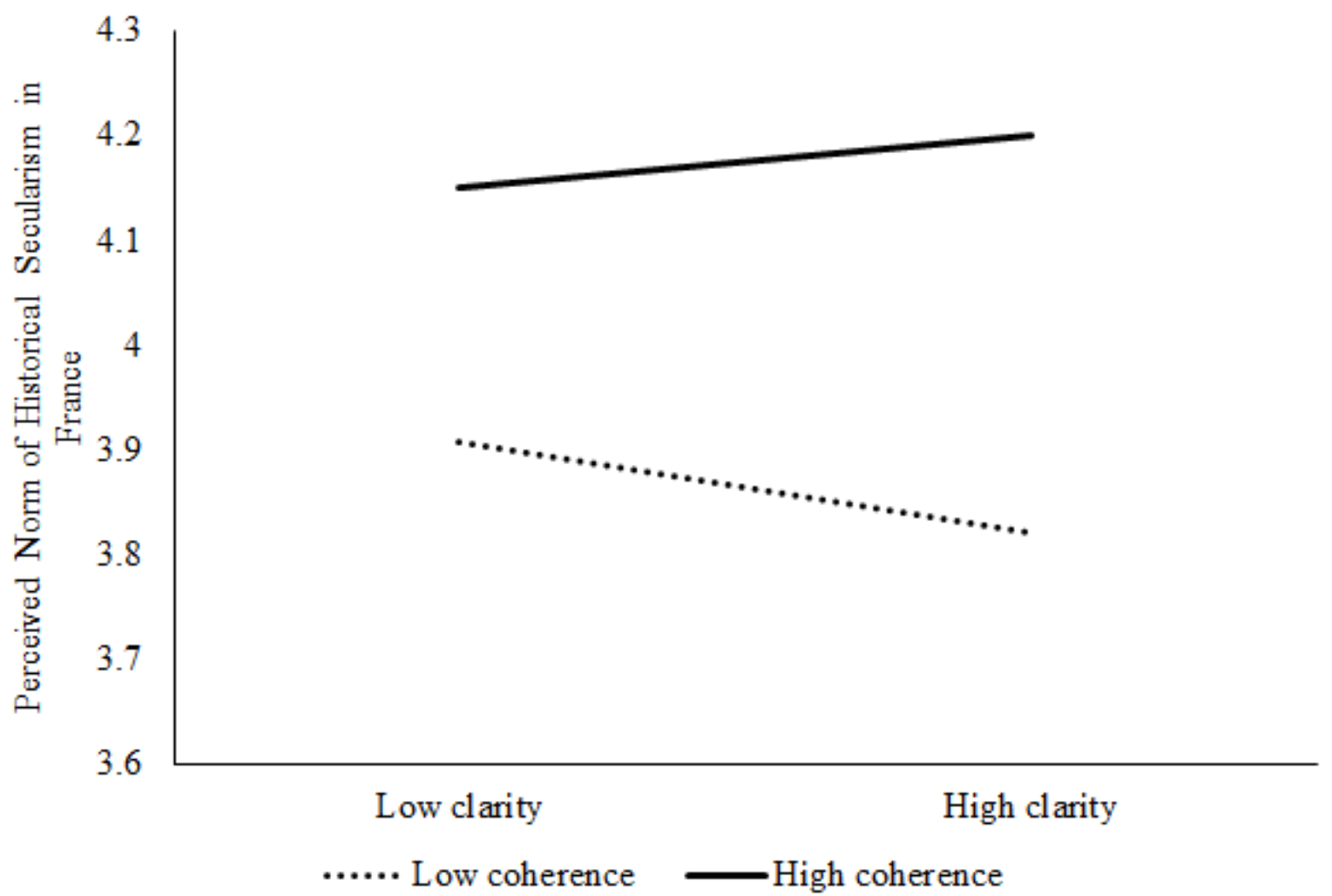

Figure 5. Interaction between clarity and coherence of integration policies on perceived norm of historical secularism (HS norm) in France. 


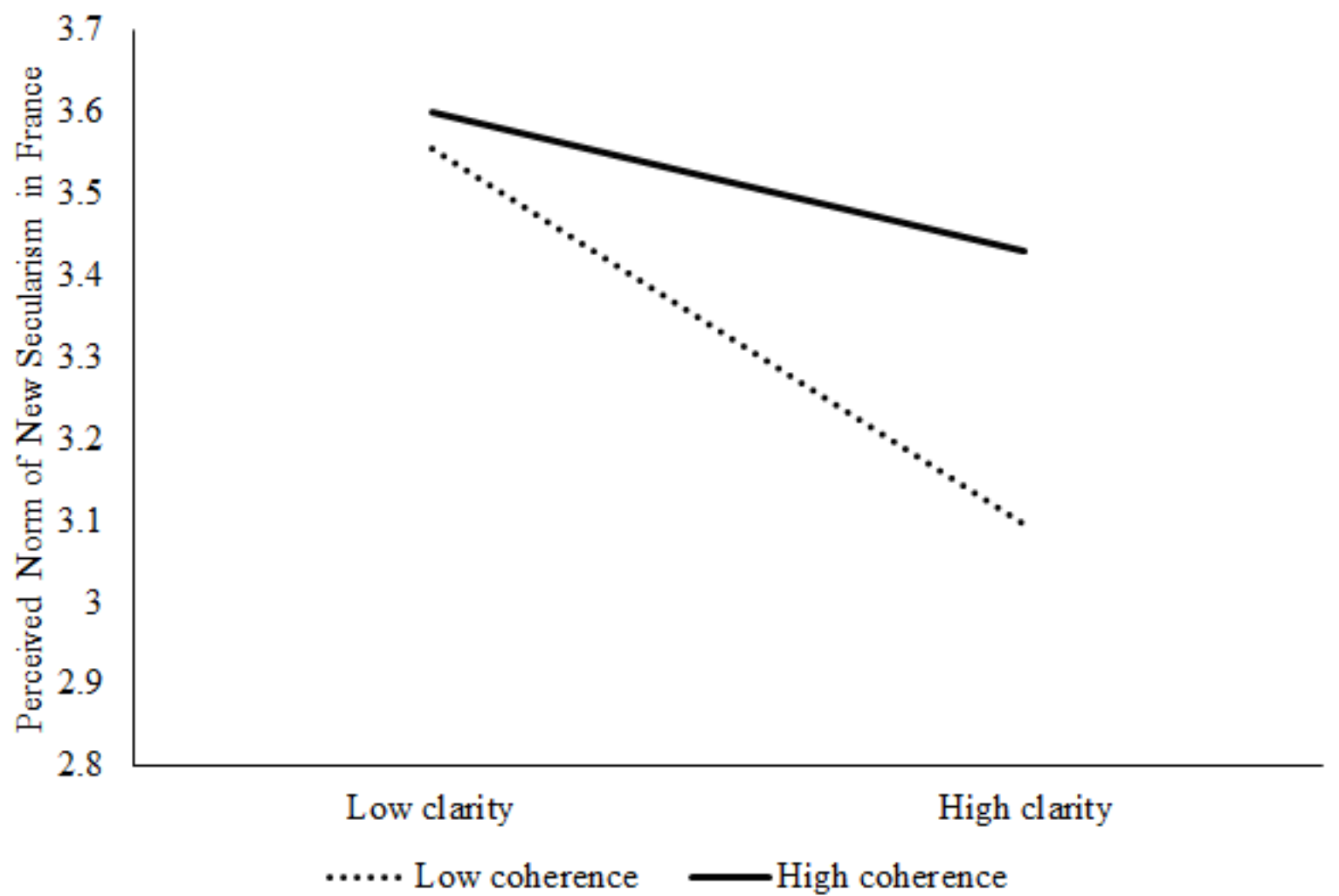

Figure 6. Interaction between clarity and coherence of integration policies on perceived norm of new secularism (NS norm) in France. 
Table 1

Clarity and Coherence of Integration Policies Items

\begin{tabular}{ll}
\hline 1. Clarity 1 & $\begin{array}{l}\text { In general, I have a clear vision of the various proposals of the government } \\
\text { regarding the integration of immigrants in France / Québec. } \\
\text { In my opinion, the various government proposals regarding the integration } \\
\text { of immigrants in France / Québec are clear. } \\
\text { The various proposals of the government regarding the integration of } \\
\text { 3. Coherence 1 }\end{array}$ \\
$\begin{array}{l}\text { 4. Coherence 2 } \\
\text { The various government proposals regarding the integration of immigrants } \\
\text { in France / Québec are part of a more global ideology. } \\
\text { The various government proposals regarding the integration of immigrants } \\
\text { in France / Québec complement each other. } \\
\text { A single ideology brings together all the government's proposals } \\
\text { concerning the integration of immigrants in France / Québec. }\end{array}$ \\
\hline
\end{tabular}


Table 2

Perceived Cultural Norms Items

\begin{tabular}{ll}
\hline 1. Assimilation 1 & The general opinion of the French / Quebecker people is that foreigners must make more efforts to \\
adapt to French / Quebecker cultural traditions insofar as they wish to live in France / Québec.
\end{tabular}

2. Assimilation 2

Most French / Quebecker people believe that life in France / Québec would be more pleasant if all individuals forgot about their ethnic and cultural differences.

3. Assimilation 3 Most French / Quebecker people consider that the unity of France / Québec is weakened by the attachment of ethnic groups to their old lifestyle.

4. Assimilation $4 \quad$ Most French / Quebecker people believe that immigrants should adapt their behavior in order to comply with that of the French / Quebecker individuals.

5. Multiculturalism 1 In general, French / Quebecker people think that immigrant parents should encourage their children to preserve the culture and traditions of their country of origin.

6. Multiculturalism 2 Most French / Quebecker people believe that ethnic minorities living in France / Québec should be helped in order to preserve their cultural heritage.

7. Multiculturalism 3 Most French / Quebecker people think that life is more pleasant in France / Québec since the different ethnic groups keep their way of life alive.

8. Multiculturalism 4 French / Quebecker people consider that a society composed of different cultural groups is better equipped to face problems that may arise.

9. Interculturalism 1 Most French / Quebecker people think that speaking French should not prevent immigrants from preserving their customs and traditions.

10. Interculturalism 2 The general opinion of French / Quebecker people is that French as a common language should not imply the abandonment of the immigrants' language(s) of origin.

11. Interculturalism 3 The general opinion of French / Quebecker people is that immigrants can be full members of the French / Quebecker society even if they do not share the style of clothing or the eating habits of a large part of the population whose ancestors lived France / Québec.

12. Interculturalism 4 The French / Quebecker people consider that exchanges and interactions between immigrants and French / Quebecker people are beneficial to the development of the French / Quebecker culture.

13. Historical In France / Québec, most people think that every citizen must be free to practice the religion of their 


\begin{tabular}{|c|c|}
\hline Secularism 1 & choice. \\
\hline $\begin{array}{l}\text { 14. Historical } \\
\text { secularism } 2\end{array}$ & $\begin{array}{l}\text { Most French / Quebecker individuals do not want people to be defined in terms of their origins, their } \\
\text { religion in France / Québec. }\end{array}$ \\
\hline $\begin{array}{l}\text { 15. Historical } \\
\text { secularism } 3\end{array}$ & $\begin{array}{l}\text { The general opinion in France / in Québec is that the French / Quebecker society is first and foremost } \\
\text { composed of citizens, and not communities. }\end{array}$ \\
\hline $\begin{array}{l}\text { 16. Historical } \\
\text { secularism } 4\end{array}$ & $\begin{array}{l}\text { The general opinion in France / Québec is that it is important to respect the equality before the law of } \\
\text { all citizens, without distinction of origin, race or religion. }\end{array}$ \\
\hline 17. New secularism 1 & In France/Québec, most people think that religious practices should be private rather than public. \\
\hline 18. New secularism 2 & $\begin{array}{l}\text { In France / Québec, most people believe that it is normal for visible religious signs to be banned in } \\
\text { public schools. }\end{array}$ \\
\hline 19. New secularism 3 & $\begin{array}{l}\text { Most French / Quebecker people are in favor of the clear separation of churches and the government in } \\
\text { France / Québec as in other countries. }\end{array}$ \\
\hline 20. New secularism 4 & $\begin{array}{l}\text { Most French / Quebecker people are opposed to the government funding the construction of religious } \\
\text { buildings. }\end{array}$ \\
\hline
\end{tabular}


Table 3

Personal Attitudes Items

1. Assimilation $1 \quad$ Foreigners must make more efforts to adapt to French / Quebecker cultural traditions insofar as they wish to live in France / Québec.

2. Assimilation 2 Life in France / Québec would be more pleasant if all individuals forgot about their ethnic and cultural differences.

3. Assimilation $3 \quad$ Unity of France / Québec is weakened by the attachment of ethnic groups to their old lifestyle.

4. Assimilation $4 \quad$ Immigrants should adapt their behavior in order to comply with that of the French / Quebecker individuals.

5. Multiculturalism 1 Immigrant parents should encourage their children to preserve the culture and traditions of their country of origin.

6. Multiculturalism 2 Ethnic minorities living in France / Québec should be helped in order to preserve their cultural heritage.

7. Multiculturalism 3 Life is more pleasant in France / Québec since the different ethnic groups keep their way of life alive.

8. Multiculturalism 4 A society composed of different cultural groups is better equipped to face problems that may arise.

9. Interculturalism 1 Exchanges and interactions between immigrants and French / Quebecker people are beneficial to the development of the French / Quebecker culture.

10. Interculturalism 2 The development of a common public culture between immigrants and French / Quebecker should be promoted.

11. Interculturalism 3 Immigrants can be full members of the French / Quebecker society even if they do not share the style of clothing or the eating habits of a large part of the population whose ancestors lived France / Québec.

12. Interculturalism 4 The French / Quebecker society must be open to the contributions coming from all parts provided human rights are respected.

13. Historical

Secularism 1

14. Historical

secularism 2

15. Historical secularism 3

I do not want people to be defined in terms of their origins, their religion in France / Québec.

Our society is first and foremost composed of citizens, and not communities. 


\begin{tabular}{ll}
\hline $\begin{array}{l}\text { 16. Historical } \\
\text { secularism 4 }\end{array}$ & $\begin{array}{l}\text { It is important to respect the equality before the law of all citizens, without distinction of origin, race or } \\
\text { religion. } \\
\text { 17. New secularism 1 }\end{array}$ \\
$\begin{array}{ll}\text { As far as possible, religious practices should be private rather than public. } \\
\text { 18. New secularism 2 }\end{array}$ & $\begin{array}{l}\text { I think that it is normal for visible religious signs to be banned in public schools. } \\
\text { 19. New secularism 3 } 3 \text { am in favor of the clear separation of churches and the government in France/Québec as in other } \\
\text { countries. }\end{array}$ \\
\begin{tabular}{l} 
I am opposed to the government funding the construction of religious buildings. \\
\hline
\end{tabular}
\end{tabular}


Table 4

Correlations among Variables and Summary of Descriptive Statistics in Québec

\begin{tabular}{|c|c|c|c|c|c|c|c|}
\hline 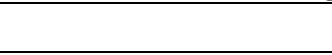 & 1. & 2. & 3. & 4. & 5. & 6. & 7. \\
\hline $\begin{array}{l}\text { 1. Clarity of } \\
\text { policies }\end{array}$ & - & $.54 * *$ & $.12 * *$ & $.07 *$ & .05 & .05 & $.10 * *$ \\
\hline $\begin{array}{l}\text { 2. Coherence of } \\
\text { policies }\end{array}$ & & - & $.18 * *$ & $.15^{* *}$ & .01 & $.07 *$ & $.10 * *$ \\
\hline 3. IC Norms & & & - & $.55^{* *}$ & $-.40 * *$ & $.18^{* *}$ & $.16^{* *}$ \\
\hline 4. Personal IC & & & & - & $-.58 * *$ & $.16^{* *}$ & $.15^{* *}$ \\
\hline 5. Prejudice & & & & & - & $-.11 * *$ & -.03 \\
\hline 6. Life satisfaction & & & & & & - & $.76 * *$ \\
\hline $\begin{array}{l}\text { 7. Subjective } \\
\text { authentic-durable } \\
\text { happiness }\end{array}$ & & & & & & & - \\
\hline Mean (SD) & $2.59(.80)$ & $2.99(.67)$ & $3.48(.77)$ & $3.69(.77)$ & $2.78(.76)$ & $3.59(.83)$ & $3.55(.72)$ \\
\hline Skewness & .23 & -.06 & -.41 & -.53 & .22 & -.50 & -.66 \\
\hline Kurtosis & -.05 & .97 & .33 & .51 & .01 & -.02 & .70 \\
\hline
\end{tabular}

Note. $* p<.05, * * p<.01$. (2-tailed). $S D=$ standard deviation; $\mathrm{IC}=$ interculturalism. 
Table 5

Correlations among Variables and Summary of Descriptive Statistics in France

\begin{tabular}{|c|c|c|c|c|c|c|c|c|c|}
\hline & 1. & 2. & 3. & 4. & 5. & 6. & 7. & 8. & 9. \\
\hline 1. Clarity of policies & - & $.49 * *$ & $.14^{* *}$ & $-.07 *$ & $.08^{*}$ & -.06 & $-.10 * *$ & $.15^{* *}$ & $.13^{* *}$ \\
\hline $\begin{array}{l}\text { 2. Coherence of } \\
\text { policies }\end{array}$ & & - & $.18^{* *}$ & .05 & $.23 * *$ & -.02 & $-.15^{* *}$ & $.14 * *$ & $.15^{* *}$ \\
\hline 3. HS Norm & & & - & $.24 * *$ & $.56^{* *}$ & $.26^{* *}$ & $-.14 * *$ & $.09 * *$ & $.11 * *$ \\
\hline 4. NS Norm & & & & - & $.20 * *$ & $.71 * *$ & .06 & .00 & .02 \\
\hline 5. Personal HS & & & & & - & $.20 * *$ & $-.49 * *$ & $.10 * *$ & $.09 * *$ \\
\hline 6. Personal NS & & & & & & - & $.11 * *$ & -.01 & .00 \\
\hline 7. Prejudice & & & & & & & - & $-.13 * *$ & $-.09 * *$ \\
\hline 8. Life satisfaction & & & & & & & & - & $.72 * *$ \\
\hline $\begin{array}{l}\text { 9. Subjective } \\
\text { authentic-durable } \\
\text { happiness }\end{array}$ & & & & & & & & & - \\
\hline Mean (SD) & $\begin{array}{l}2.55 \\
(.94)\end{array}$ & $2.97(.75)$ & $3.81(.80)$ & $3.94(.76)$ & $3.89(.84)$ & $4.06(.77)$ & $\begin{array}{l}3.10 \\
(.86)\end{array}$ & $\begin{array}{l}3.20 \\
(.85)\end{array}$ & $\begin{array}{l}3.20 \\
(.73)\end{array}$ \\
\hline Skewness & .28 & -.04 & -.73 & -.81 & -.79 & -.67 & -.11 & -.41 & -.38 \\
\hline Kurtosis & -.28 & .95 & .86 & 1.19 & .81 & .26 & -.44 & -.18 & .13 \\
\hline
\end{tabular}

Note. $* p<.05, * * p<.01$. (2-tailed). $S D=$ standard deviation; $\mathrm{HS}=$ historical secularism; $\mathrm{NS}=$ new secularism 
Table 6

Mean Positive Value Attached to Four Models, by Country ( 1 = Very Negative, 4 = Very Positive $)$

\begin{tabular}{lcccc} 
& \multicolumn{4}{c}{ Models Evaluated } \\
\cline { 2 - 5 } Country & Secularism & Interculturalism & Multiculturalism & Assimilation \\
\hline \multirow{3}{*}{ France } & $M(S D)$ & $M(S D)$ & $M(S D)$ & $M(S D)$ \\
Québec & $3.42(.73)$ & $2.85_{\mathrm{ab}}(.86)$ & $2.83_{\mathrm{ac}}(.89)$ & $2.76_{\mathrm{bc}}(.85)$ \\
\hline
\end{tabular}

Note. Identical subscripts indicate non-significant differences within each row at $p<.05$ (Bonferroni corrected) 
Table S1

Correlations Between Measures of Perceived Cultural Norms in France and in Québec

\begin{tabular}{|c|c|c|c|c|c|}
\hline Variable & 1. & 2. & 3. & 4. & 5. \\
\hline 1. MC norm & - & $-.32 * *$ & $.36 * *$ & $-.08 *$ & $.66 * *$ \\
\hline 2. AS norm & $-.33 * *$ & - & $.13^{* *}$ & $.37 * *$ & $-.21 * *$ \\
\hline 3. HS norm & $.33 * *$ & $.07 *$ & $\ldots$ & $.24 * *$ & $.47 * *$ \\
\hline 4. NS norm & .02 & $.22 * *$ & $.38 * *$ & - & .02 \\
\hline 5. IC norm & $.53 * *$ & $-.13 * *$ & $.51 * *$ & $.22 * *$ & $=$ \\
\hline
\end{tabular}

Note. $\mathrm{MC}=$ multiculturalism; $\mathrm{AS}=$ assimilation $; \mathrm{HS}=$ historical secularism; $\mathrm{NS}=$ new secularism; $\mathrm{IC}=$ interculturalism. Correlations for Québec in lower left; Correlations for France in upper right. $* p<.05, * * p<.01$. 
Table S2

Correlations Between Measures of Personal Attitudes toward Policies in France and in Québec

\begin{tabular}{|c|c|c|c|c|c|}
\hline Variable & 1. & 2. & 3. & 4. & 5. \\
\hline 1. Personal MC & - & $-.44 * *$ & $.45 * *$ & $-.10 * *$ & $.68 * *$ \\
\hline 2. Personal AS & $-.42 * *$ & 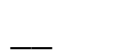 & $-.15 * *$ & $.39 * *$ & $-.36 * *$ \\
\hline 3. Personal HS & $.35 * *$ & -.01 & - & $.20 * *$ & $.61 * *$ \\
\hline 4. Personal NS & .02 & $.16^{* *}$ & $.34 * *$ & - & .04 \\
\hline 5. Personal IC & $.57 * *$ & $-.21 * *$ & $.60 * *$ & $.25 * *$ & 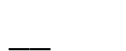 \\
\hline
\end{tabular}

Note . MC = multiculturalism; AS = assimilation; HS = historical secularism; NS = new secularism; IC = interculturalism. Correlations for Québec in lower left; Correlations for France in upper right. ${ }^{*} p<.05, * * p<.01$. 
Table S3

Prejudice Items

\begin{tabular}{ll}
\hline 1. Prejudice 1 & When jobs are scarce, French [Quebecers] people should have priority over immigrants for employment. \\
2. Prejudice 2 & $\begin{array}{l}\text { When the level of unemployment is high, this is usually because foreigners take the jobs of French [Quebecers]. } \\
\text { people. }\end{array}$ \\
$\begin{array}{ll}\text { 3. Prejudice } 3 & \text { Personally, I would have no problem moving into a neighbourhood where many immigrants live. (reversed item) } \\
\text { 4. Prejudice } 4 & \text { Nowadays, there are too many immigrants in France[Québec]. } \\
\text { 5. Prejudice } 5 & \text { It is a bad idea for people of different races/ethnicities to marry one another. } \\
\text { 6. Prejudice 6 } & \text { I consider our society to be unfair to immigrants. (reversed item) }\end{array}$ \\
\hline
\end{tabular}


Table S4

Results of Hierarchical Multiple Regression Predicting the Evaluative Meaning of Secularism from Perceived Norms in France

\begin{tabular}{lcccc}
\hline & $R^{2}$ & $\Delta R^{2}$ & $F$ & $\beta$ \\
\hline Step 1 & .13 & .13 & $64.44^{* * *}$ & \\
Historical Secularism & & & $.17^{* * *}$ \\
New Secularism & & & $.28^{* * *}$ \\
Step 2 & .13 & .00 & $25.80^{* * *}$ & \\
Historical Secularism & & & $.18^{* * *}$ \\
New Secularism & & & $.29^{* * *}$ \\
Multiculturalism & & & -.02 \\
Assimilation & & & -.02 \\
Interculturalism & & & .00 \\
\hline
\end{tabular}

Note. ${ }^{*} p<.05 ; * * p<.01 ; * * * p<.001$. 
Table S5

Results of Hierarchical Multiple Regression Predicting Evaluative Meaning of Interculturalism from Perceived Norms in Québec

\begin{tabular}{lcccc}
\hline & $R^{2}$ & $\Delta R^{2}$ & $F$ & $\beta$ \\
\hline Step 1 & .11 & .11 & $99.13^{* * *}$ & \\
Interculturalism & & & $.33^{* * *}$ \\
Step 2 & .15 & .04 & $47.11^{* * *}$ & \\
Interculturalism & & & $.21^{* * *}$ \\
Multiculturalism & & & $.21^{* * *}$ \\
Assimilation & & & -.06 \\
Step 3 & .16 & .01 & $29.52^{* * *}$ & \\
Interculturalism & & & $.19^{* * *}$ \\
Multiculturalism & & & $.21^{* * *}$ \\
Assimilation & & & $-.08^{*}$ \\
New Secularism & & & $.08^{*}$ \\
Historical Secularism & & & .02 \\
\hline
\end{tabular}

Note. $* p<.05 ; * * p<.01 ; * * * p<.001$. 


\section{Table S6}

Results of ANCOVAs Comparing Mean Scores of Perceived Norms Between Countries

\begin{tabular}{lcccc}
\hline & $F(d f)$ & $\eta_{p}{ }^{2}$ & $M(S E)_{\text {Québec }}$ & $M(S E)_{\text {France }}$ \\
\hline Historical Secularism & $1.77(1,1846)$ & .001 & $3.80(.02)$ & $3.84(.02)$ \\
New Secularism & $44.14(1,1846)^{* * *}$ & .023 & $3.71(.03)$ & $3.95(.03)$ \\
Interculturalism & $96.66(1,1846)^{* * *}$ & .050 & $3.46(.02)$ & $3.18(.02)$ \\
Assimilation & $.31(1,1846)$ & .000 & $3.93(.02)$ & $3.91(.02)$ \\
Multiculturalism & $16.42(1,1846)^{* * *}$ & .009 & $2.73(.02)$ & $2.85(.02)$ \\
\hline
\end{tabular}

Note. $* p<.05, * * p<.01, * * * p<.001$. All means are estimated. This series of ANCOVAs tested country differences on a given measure of perceived cultural norm, controlling for all four other measures of perceived norms. 